\title{
THE INTRAORAL TELEVISION \\ MICROMEASUREMENT OF CAVITY MARGIN DETERIORATION
}

Burton Allan Horwitz

Submitted to the Faculty of the Graduate School in partial fulfillment of the requirements for the degree of Niaster of Science of Dentistry, Indiana University, School of Dentistry, 1966. 
ACKNOWLEDGMENTS 
The author wishes to express his gratitude to Dr. Ralph E. McDonald for his guidance and inspiration during the author's pedodontic graduate program.

The author wishes to express his sincere gratitude to Dr. Arthur I. Klein. Without his patience, understanding, and wise counsel, the preparation and completion of this thesis would have been impossible.

The author wishes to thank Dr. Paul Starkey for his interest and stimulation during the author's graduate program.

The author wishes to thank Mr. Dwight MacPherson for his assistance in the technical procedures of the television microscope. His devotion to this project is gratefully acknowledged.

The author wishes to thank Miss Rosemary Rocap for her assistance in the administration of this research project. Her friendship and devotion will always be held in the highest esteem by the author.

The author wishes to thank Mr. Richard Scott for his assistance in compiling the photographic portions of this thesis.

The author wishes to take this opportunity to thank his parents for their continued inspiration and faith throughout his academic 
career.

The author wishes to thank his wife, Nichele, for her assistance in the typing of this thesis. He also wishes to express his gratitude for her faith, inspiration and encouragement during the author's pedodontic graduate program. 
TABLE OF CONTENTS 
TABLE OF CONTENTS

Page

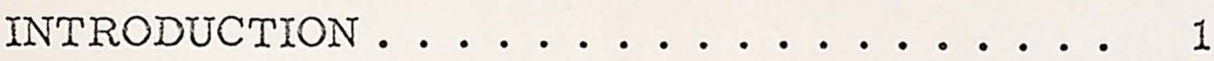

REVIEW OF THE LTTERATURE

I. Physical Properties of Amalgam as Related to Marginal Failure ......... 3

II. Class II Cavity Preparation of Deciduous Second Molars . . . . . . . . 23

III. Television Instrumentation . . . . . 28 STATEMENT OF PROBLEN . .......... 30 EXPERIMENTAI PROCEDURES

I. Clinical Operative Procedures ..... 31

II. Laboratory Procedures........ 35

III. Television Microscopy Evaluation Procedure............ 37

IV. Television Instrumentation ...... 38 $\mathrm{DATA}_{2 \ldots \ldots \ldots \ldots \ldots \ldots \ldots} \ldots \ldots \ldots$

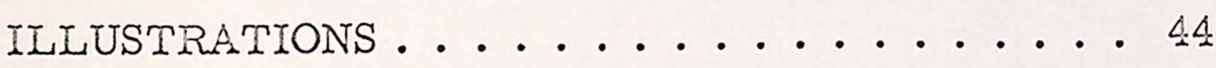

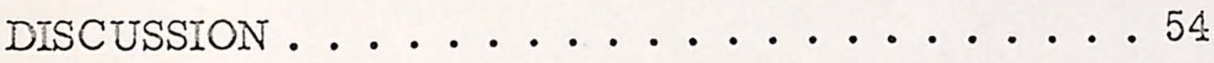
SUMMMARY AND CONCLUSIONS ......... 59

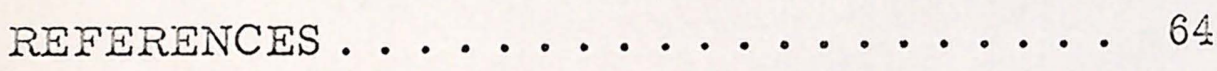
CURRICULUM VITAE ABSTRACT 
LIST OF ILLUSTRATIONS 


\section{LIST OF ILLUSTRATIONS}

Page

Figure 1. The clinical and laboratory procedure for the television microscope . . . . . 44

Figure 2. A cast gold overlay with viewing holes . 45

Figure 3. Serial television gingival micromeasurement photographs indicating the line of measurement .......... 46

Figure 4. A block diagram of the intraoral microscope system ......... 47

Figure 5. A labeled photograph of the intraoral microscope assembly ....... 48

Figure 6. The intraoral television microscope clinically viewing the mesiobuccal margin of a second deciduous molar . .

A closeup photograph demonstrating the relationship of the objective lens of the microscope to the gold overlay ...

Figure 7. An overall view of the television

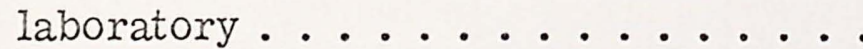

Figure 8. A graph showing the average marginal deterioration for the occlusal and gingival areas...........

Figure 9. A bar graph demonstrating the average micron and percent marginal deteriora-

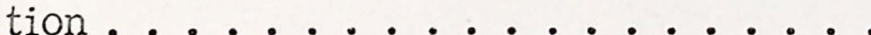

Figure 10. Serial television micromeasurement photographs indicating an area of progressive marginal deterioration ..... 
INTRODUCTION 
Most clinical dental research of the oral cavity is conducted with the naked eye, or at best, a few times magnification with the aid of binocular loops. Higher magnification is impossible due to the bulkiness of the equipment and the necessity for observing at the low light levels found in the oral cavity of the human and experimental animal. The television microscope eliminates this problem by obtaining clinically high magnifications and accurate measurements utilizing electronically controlled lightness, brightness, and scanning measurement techniques.

A great deal has been said and written about the cavosurface margins where amalgam is being used. The profession has long realized that it is at this point where many of the restoration failures take place. It has been assumed that these failures are due to faulty cavity preparation and restorative manipulation. In addition, little is known concerning the extent, the character, and the nature of cavosurface failures of amalgam restorations. Since this cavosurface junction is critical, relative to cavity preparation, filling manipulation, and the permanence of the restoration, more critical methods for the accurate evaluation of these procedures should be developed. 
A study was designed to measure the marginal deterioration of alloy restorations in deciduous teeth, utilizing the television microscope for precise intraoral micromeasurements. This study was intended to demonstrate the clinical application of the television microscope in dental research and the nature and extent of proximal marginal deterioration of alloy restorations in deciduous teeth. 
REVIEW OF THE LITERATURE 
The review of the literature is divided into three subheadings relative to the subject of marginal deterioration of amalgam restorations. These topics are Physical Properties of Amalgam as Related to Marginal Failure, Class II Cavity Preparation of Deciduous Molars, and the Television Instrumentation.

\section{$\frac{\text { Physical Properties of Amalgam as }}{\text { Related to Marginal Failure }}$}

Black ${ }^{1}$ was one of the first investigators to recognize the importance of studying the influence of manipulative variables on the properties of amalgam as it related to marginal adaptation. Fie ma de observations of the influence of residual mercury on the resistance of the material to crushing stresses. However, Black was hampered by inaccurate instruments with which to demonstrate the relationship of these two factors.

The relationship of residual mercury to the physical properties and clinical behavior of amalgam has occupied the interest of numerous investigators in the past. Gray, 2,3 in 1919, made important observations on the relation between residual mercury and the physical properties of amalgam. He stressed 
the importance of maintaining an accurate mercury/alloy ratio. However, he noted that a sound condensation technique lessened the significance of the mercury/alloy ratiofactor.

Phillips and Boyd ${ }^{4}$ investigated the importance of the mercury/alloy ratio to the amalgam filling. They found that the percent of residual mercury increased proportionately as the mercury/alloy ratio increased. Excess mercury used in trituration increased the flow and decreased the resistance of the alloy to tarnish and corrosion. Furthermore, as the mercury/alloy ratio was increased, the crushing strength decreased for both onehour and 24-hour tests. Phillips and Swartz 5 continued to investigate the effects of residual mercury in amalgam restorations and found that the average mercury content of 100 alloys was 45.4 percent, with extremes of 28.6 percent and 61.0 percent. They concluded that the amount of mercury remaining in the amalgam should be minimized to assure maximum strength and resistance to tarnish.

Nadal, Phillips, and Swartz $6,7,8$ conducted a clinical investigation of the relation of mercury to the amalgam restoration. They placed 257 amalgam restorations in standardized preparations. Using three different techniques, they produced restorations of three widely different mercury contents and, therefore, three different sets of physical 
properties. They found no failures due to flow or dimensional change. A definite relation between marginal deterioration and mercury content was discovered; the number and severity of marginal failures increased as the mercury content increased. Surface roughness and general degradation were manifested by many of the restorations containing 58 percent mercury, and this roughness and degradation increased even more in the group containing 62 percent mercury.

Swartz and Phillips ${ }^{9}$ also studied the residual mercury content of amalgam restorations as related to its influence on compressive strength. They stated that the residual mercury content was dependent on two factors, the original mercury/alloy ratio and the condensing pressure. No correlation between strength and residual mercury was observed when the residual mercury content was 45 to 53 percent. A direct relationship was found between compressive strength and residual mercury content when 55 percent residual mercury or more was obtained; the strength of the amalgam decreased sharply when 55 percent residual mercury was reached. They found that it was quite common to find the marginal areas exceeding 55 percent when the average residual mercury content for the entire restoration was less that 55 percent. Wilson, Phillips, and Norman ${ }^{10}$ found that 
regardless of the method of condensation or the dryness of the alloy increments, the marginal areas of the amalgam contained a higher percentage of mercury than did the bulk of the alloy.

Wolcott ${ }^{11}$ examined the effect of increasing the mercury/alloy ratio. He found that this increased the residual mercury, thereby reducing the strength, increasing the flow, and increasing the susceptibility to tarnish and corrosion. He further found that a serious loss in strength occurred when the residual mercury exceeded 55 percent. These findings corroborated the results of previous investigations by Swartz and Phillips. 9

One can conclude from these studies concerning residual mercury in alloy restorations that a reduction in strength, and an increase inflow, and an increase in susceptibility to tarnish and corrosion is effected when the residual mercury content of an alloy reaches 55 percent. Furthermore, one can conclude that the marginal areas of an amalgam contain a higher percentage of residual mercury than the bulk of the alloy. An increased residual mercury content, however, seems to have little affect on flow or dimensional change as related to failures in amalgam restorations. The effect of residual mercury appears to be far more pronounced in the marginal areas where surface roughness and mar- 
ginal deterioration was far more prevalent as the residual mercury content approached 58 percent.

Compressive strength appears to be a property of amalgam that has prompted some investigations as to its nature. Ward 12 first noted the influence of the rate of load application on the strength values of alloy restorations. He proved that the faster the load application, the higher the strength value became. This principle led to the observation that the strength properties of amalgam were influenced not only by the type of stress but also by the length of time that the restoration was subjected to the stress.

Phillips ${ }^{13}$ studied six alloys to determine their compressive strength as related to time. He found that the alloy was very weak in the first few hours after insertion. It gained strength rapidly and reached approximately 85 percent of its maximum strength by the end of the first eight hours. The compressive strength continued to increase gradually up to the six-month final test. He co ncluded that equilibrium in amalgam is not reached for an indefinite period of time. Taylor and others ${ }^{14}$ agreed with Phillips and recommended that no stress be applied to amalgam less than one hour old and further suggested that any mastication on an amalgam less than six hours old would cause damage. 
Crowell and Phillips ${ }^{15}$ determined the relationship between the surface area of alloy particles and compressive strength. They found that the compressive strength increased as the surface area of the alloy chips increased for both one-hour tests and $24-$ hour tests.

The property of flow has been considered by many to be of extreme clinical importance. Ward and $\operatorname{scott} 16$ found that amalgam exhibited 63 times more flow than gold. They concluded that it took only a small force to cause the proximal portions of alloy restorations in molars and bicuspids to move. Further investigations by Skinner ${ }^{17}$ led him to conclude that neither method nor time of trituration greatly affected the property of flow.

Sweeney 18,19 conducted comparative studies on the effect of manual and mechanical condensation techniques on the physical properties of amalgam. He concluded that the pneumatic condenser permitted the operator to condense amalgam in a less plastic state. The pneumatic condenser made adaptation possible without excess mercury being present in the original mix. Distortion of mechanically condensed restorations appeared to be less than in those restorations packed by uncontrolled hand methods. The most important contribution made by $\mathrm{Sweeney}$ in his studies was that he found no clinical evidence of flow even though alloys of high flow values were used. He 
concluded that flow was not an important cause of failure. Delayed expansion or contraction appeared to be far more important in assessing the clinical failure of amalgam restorations. Nadal, Phillips, and Swartz ${ }^{6,7,8}$ corroborated these conclusions on the clinical significance of flow many years later.

Phillips, Boyd, Healey, and Crawford 20,21 conducted a clinical study on 130 restorations placed in both adults and children. These restorations were placed by three different techniques. Approximately one-third were underamalgamated, one-third were mixed according to instructions, and one-third were triturated for three minutes. Clinically, there was not much difference between the three techniques. Based on clinical examinations, the threeminute mix exhibited less tarnish and corrosion, closer adaptation to the cavity walls, and a slight contraction. In contrast, the undertriturated amalgam exhibited more expansion and tarnished easily. No clinical evidence of flow was encountered regardless of the technique used.

Jarabak 22 continued investigations of the effect of alloy particle size on the dimensional change of amalgam. He found that expansion decreased as the particle size of the alloy became smaller. Furthermore, it was found that as the particle size became smaller, the effects of trituration time and condensation 
on dimensional change became less apparent. In contrast to previous investigators, Jarabak found no difference between mechanical condensation and hand co ndensation on dimensional change.

Phillips, 23 in 1944 , compared the influence of the me chanical amalgamator and the pneumatic condenser on the physical properties of amalgam. He concluded that the me chanical amalgamator produced more thorough mixing, caused a slight contraction and more flow, but increased the one-hour and $24-$ hour compressive strengths of the amalgam. The pneumatic condenser, however, had little effect on dimensional change or flow. This fact confirmed Jarabak's conclusions on the relationship of mechanical condensation to dimensional change.

Sweeney ${ }^{24}$ analyzed several aspects of amalgam manipulation and proposed some manipulative concepts. He stressed complete amalgamation, removal of excess mercury prior to condensation, and condensation of small increments of amalgam to activate excess mercury to the surface of ea ch layer. These three principles will provide an amalgam of low mercury content, thus effecting a decrease in flow and an increase in compressive strength. Homogeneity throughout the restoration was proposed by sweeney as an essential principle for resistance to corrosion.

Ryge and others ${ }^{25}$ compared the effects of 
three mechanical condensers and three handpacking techniques on compressive strength, dimensional change, mercury content, and microstructure. They found that mechanical condensation caused higher compressive strengths and slight contraction. However, no relationship was found between mercury content and the compressive strength, the dimensional change, or the microstructure of amalgam.

Crawford and Larson ${ }^{2} 6$ refuted Ryge and found that there was no difference in compressive strength when using either hand condensation or mechanical condensation techniques. They also found that longer mechanical trituration times resulted in an increase in strength and a decrease in expansion. They confirmed that within certain limits mercury content alone could not be used to predict strength, nor was there any correlation between mercury content and strength or dimensional change of the alloy.

Swartz and Phillips 27 found no correlation between the physical properties of amalgam or residual mercury content with any specific method of condensation. They stressed that if a sound technique for removing mercury from individual increments was employed with a carefully standardized condensation procedure, no differences in the physical properties of the alloy would be found. This lends credence 
to earlier statements by Sweeney 28 in which he strongly condemned the use of small pluggers for condensation and burnishing inside the cavity. He stated that small pluggers merely push the amalgam from one place to another, thus not realizing proper condensation. He also concluded that burnishing caused weak amalgam to be deposited in the sharp angles of the restoration where the strongest alloy is desired.

Most of the techniques employed in trituration and condensation of amalgam stress the "increasing dryness" technique. However, there are now many advocates of a technique whereby amalgam of the same consistency is condensed throughout the cavity preparation.

Strader 29 first recommended condensing amalgam of the same plasticity from the bottom to the top of the restoration in order to minimize or eliminate unequal expansion and flow. Mosteller 30 advocated a dry mix of amalgam from start to finish of condensation to minimize expansion.

Eames 31,32 proposed that a well-condensed amalgam should contain less than 50 percent residual mercury. He showed that an amalgam mass could be triturated containing a nearoptimum ratio of less that 50 percent mercury. Eames maintained, after a four-year study, that this amalgam exhibited more desirable clinical properties in condensation and 
manipulation, since mulling and removing excess mercury with instruments is virtually eliminated. Furthermore, this technique provided early strength values considerably higher than those usually expected. Wolcott, Jendresen, and Ryge 33,34 investigated the strength, dimensional change, and adaptation of amalgam prepared with a 1:1 ratio of mercury to alloy. They found that successful amalgam with a low mercury content and high strength could be produced by this technique. No difference in adaptation was noted, nor was a slight contraction due to increased trituration time considered clinically significant.

Expansion and contraction of dental amalgam has been a subject of repeated investigation. Schoonover, Souder, and Beall 35 investigated expansion and contraction of dental amalgam. They stated:

Expansion may cause extension of the restoration beyond the tooth margins

Contraction causes the separation of the re storation from the retaining walls of the tooth, resulting in leakage and thus inviting recurrent decay.

They concluded that excessive expansion does not occur uniess the alloy is contaminated by moisture.

Miller $36,37,38$ formulated several clinical principles and procedures to minimize failure of amalgam restorations. He stated that the prerequisites to a successful amalgam included the 
use of an accepted alloy, correct cavity preparation, the use of the rubber dam during the condensation and carving procedures, the application of an unyielding matrix band, and intelligent management of amalgam. Miller concluded that moisture contamination should be avoided at all times, thus emphasizing the need for the rubber dam. He stressed the importance of maintaining exact mercury/ alloy ratios, complete trituration, and uniform filling material from the floor of the cavity to the occlusal surface. Romnes ${ }^{39}$ further defined the effect of moisture contamination on amalgam. He stated that saliva or moisture interfered with cohesion. Marginal leakage occurred due to the dissolution of salivary salts. Moisture contamination also caused a decrease in crushing strength, delayed expansion, and a decrease in resistance to corrosion.

Phillips 40 referred to the A. D.A. specification that amalgam should expand between three and 13 microns per centimeter 24 hours postoperatively. He stated, however, that moisture contamination sometimes caused several hundred microns expansion for the same time period. This led to an investigation on the effects of contracting alloy restorations. McDonald and Philips ${ }^{41}$ placed 60 contracting alloy restorations in children to determine the clinical significance of open margins or recurrent caries and concluded that contraction 
resulting from slight overtrituration is not clinically observable. Mosteller 42 confirmed this observation by stating that slight contraction is of no clinic al importance, whereas excessive expansion of the alloy will result in failure of the restoration.

Many investigators have attempted to define and categorize the reason for failure of amalgam restorations. Ottolengui 43 stated, in 1925 , that the greatest percentage of failures occur on the proximal surfaces due to the dificulty of properly inserting and polishing the restoration. Byrnes 44 agreed and stated that there were two main reasons for proximal occlusal alloy restoration failure: 1. faulty adaptation to the cavity wall, which was attributed to the lack of the development of a matrix which would adequately withstand the forces of condensation, and 2. the poor edge strength of amalgam.

Schoonover and Souder 45 found a definite relationship between corrosion of dental alloys and the extent to which the alloys sealed the cavity preparations. They examined 50 freshly extracted teeth containing amalgam restorations. Corrosion was observed at the base of all amalgam restorations in which the fillings evidently failed to seal the cavity. Thorough amalgamation, accurate condensing procedures, and careful polishing were considered essential to prevent or minimize corrosion of alloy 
restorations.

An important study on the causes and prevention of amalgam failures was conducted by Easton, 46 in 1941. He examined 415 alloys to determine the causes of failure. One or both proximal surfaces were cariously involved in 274 of these failures. In only one-third of the failures was the causative defect Iimited to the occlusal surface only. A V-shaped fracture of the alloy at the buccal and Iingual margins of the proximal walls from gingival to occlusal was found in 23 percent of these failures. It was difficult to determine the causes of this fracture with accuracy. How ever, the outline form was observed to be faulty to the extent that the fracture could have been attributed to a weakness of the alloy at the margins. This substantiated Tingley 47 who said:

We ought not to lose sight of the fact that enamel is very friable material and that enamel cavosurface margins on occasions do fracture. Discrepancies resulting from breakage of either the enamel or the amalgam serve to cause the failure of our restoration.

Predicated on the fact that enamel was very friable and that enamel cavosurface margins occasionally fracture because of this friability, Kornfeld 48 recommended that cavity walls follow the direction of the enamel rods of the tooth for maximum strength and prevention of 
amalgam and enamel fractures at the margins. Healey and Phillips 49 examined 1521 defective amalgam restorations to determine the causes of failure. They found that the main causes of failure were recurrent caries, fracture, dimensional change, and pulp or periodontal involvement. Improper cavity preparation accounted for 56 percent of all failures. Faulty manipulation of amalgam or its contamination at the time of insertion accounted for 40 percent of all failures. Improper cavity preparation and failure of the material itself were contributing factors to recurrent caries. Fracture of the amalgam accounted for 26.2 percent of the failures. Faulty manipulation of the alloy, improper mercury/alloy ratios, and improper cavity preparations were contributing factors to fractures of the amalgam. These fractures included serious marginal breakdown in the proximal flare and occlusal areas. Dimensional changes, 16.6 percent of all failures, were caused primarily by moisture contamination during condensation.

The most frequent causes of failure of amalgam restorations have since been corroborated by many investigators. Moss 50 investigated amalgam failure in the United States Armed Forces and found that 83.8 percent of all failures were caused by incorrect cavity preparation. Ingraham 51 stated that 
underextended margins was a major cause of marginal failure. Kroll, 52 Richardson, 53 Hailey, 54 and Wiggins 55 confirmed the factors of improper cavity preparation and faulty manipulation as the major causes of amalgam failure. They emphasized the contributing manipulative errors of undertrituration, excessive mercury, improper condensation, and moisture contamination. Wilson and Ryge 56 observed 500 restorations for six, twelve, and eighteen months and found that the effects of manipulative variables, matrix stability, and finishing procedures were far more pronounced than differences due to zinc content or particle size of the alloy. Deschenes ${ }^{57}$ further defined the specific errors in cavity preparation to include incomplete caries removal, insufficient extension, faulty retentive form, lack of cavity depth, and fragility of the cavoperipheral angle. He also corroborated the manipulative errors previously discussed.

Castaldi 58 studied 1,009 proximal occlusal amalgam restorations in deciduous teeth and found that proximal margin defects occurred frequently, particularly on the distobuccal margins of mandibular primary first molars. He altered the cavity design by capping the distobuccal cusp, and the incidence of proximal margin defects decreased from 29.04 percent to five percent. Fritz, 59 Simon, 60 Markley, 61 Miller, 62 and Anderson 63 
stressed the fact that amalgam has no edge strength. Most investigators consider edge strength to be indicative of the ability of fine margins to resist fracture or abrasion. It is considered a critical property of amalgam and must be compensated by preparing the proximal surfaces so that they are parallel to the enamel rods and form a ninety degree cavosurface angle.

MacRae, Zacherl, and Castaldi 64 conducted a four-year study of defects in Class II amalgam restorations in deciduous molars. They examined 1,009 restorations and found that proximal margin defects occurred more frequently than any other type of defect. It was found that failure of the amalgam itself was responsible for more marginal defects than breakdown of the enamel. In almost all cases, these defects occurred between six and twelve months postoperatively. They suggested that these findings indicated the need for a better filling material or alternative methods for restoring these teeth.

Marginal adaptation to the cavity walls is of primary concern to investigators studying marginal failures of amalgam restorations. Bjorndal and Sahs 65 conducted a comparative photomicrographic study of marginal adaptation of gold inlays and amalgams. These teeth were extracted and magnified 60 times. Amalgam restorations were found to have far 
better adaptation properties than gold inlays, but it is evident from the photomicrographs that there are many irregularities and voids in the cavosurface margins of the amalgam restorations.

Hatt 66 studied the effect on amalgam adaptation to the cavity wall as influenced by the following factors: 1. varying the amount of mercury expelied immediately after trituration and prior to condensation, 2. varying the condensation method, and 3. varying the condensation pressure. He made 194 specimens by condensing into an artificial cavity designed to simulate the proximal aspect of Black's Class II cavity. A Talysurf surface analyser was used to assess the quality of adaptation. The average residual mercury content was 48.9 percent. Hatt found th at the amount of mercury expelied had no effect on adaptation as long as the amount of mercury eliminated was between 20 and 25 percent for hand condensation and between 25 and 30 percent for mechanical condensation. The ideal hand condensing pressure was found to be 2800 pounds per square inch. Using a condenser point whose outline gained access to the line angles, the average size of the space between the amalgam and the cavity wall was 60 micro-inches and 76 micro-inches along the cavosurface angle. Using a circular condensing point, the average size of the spaces was 66 and 140 micro-inches for 
the cavity wall and the cavosurface angle, respectively. Using a mechanical condenser, the space was 25 and 38 micro-inches for the cavity wall and the cavosurface angle, thus indicating better adaptation using a mechanical condenser.

Nelsen, Wolcott, and Paffenbarger 67

studied fluid exchanges at the margins of dental restorations and found that temperature changes in the mouth caused a fluid exchange between the teeth and amalgam restorations. This marginal percolation is caused by a difference in the coefficient of thermal expansion of the tooth and the restoration and by thermal expansion of the fluid occupying the crevice between the tooth and the restoration. Armstrong and Simon 68 and Phillips 69 investigated the penetration of radioactive isotopes at the margins of filling materials and found less penetration at the margins of amalgams than with other materials. Furthermore, Phillips found that marginal penetration of amalgams decreased with the age of the restoration. Weinstock ${ }^{70}$ investigated the ability of amalgam to seal a prepared cavity and found that it exhibited 100 percent seepage to bacteria and fluid at the margins within eight days postoperatively. Phillips, Gilmore, Swartz, and Schenker 71 found, with the use of $\mathrm{Ca}^{45}$, that the margins of amalgam were readily penetrated by the isotope initially. This leakage 
diminished as the restoration aged. These findings were confirmed by Brannstrom and Soremark72 using $\mathrm{Na}^{2} 2$ ions. They also found that penetration was greater around amalgams that were not insulated with a varnish. Baumgartner, Bustard, and Feierabend 73 conducted similar studies using $\mathrm{I}^{131}$ ions and found similar results.

Jorgensen 74,75 conducted an important study of the mechanism leading to fracture of the margins of an amalgam restoration. The most essential reason for slits or voids occurring between the amalgam margin and the cavity wall is corrosion with resulting "mercuroscopic" expansion. The amalgam surface facing the cavity wall functions as an anode in a concentration cell element where the cathode is the free surface of the filling. Due to the anodic corrosion, metallic mercury is set free; the mercury diffuses into the amalgam from the cavity side and causes a unilateral expansion of the wedge-shaped amalgam margin which bends away from the supporting enamel wall. Other reasons for deformation of slits are delayed expansion, condensing failures, flow, marginal excess, enamel fractures, and caries. Jorgensen 74,75 further outlined some factors that he believes are significant in "mercuroscopic" marginal deflection. Omission of the electrolyte from the interface between amalgam and tooth 
structure is important. This omission can be obtained only by the greatest possible adaptability, the smallest possible setting expansion or contraction, a certain degree of roughness of the cavity wall, parallelism between the cavity wall, and omission of delayed expansion. The greatest posible strength of amalgam may also improve the stability between tooth and filling. Jorgensen 74,75 also stated that the reduction of the mercury content in the margins to a minimum and to the same value as the bulk of the fillings was very important in "mercuroscopic" marginal deflection.

$\frac{\text { Class II Cavity Preparation of }}{\text { Deciduous Second Molars }}$

The importance of correct cavity preparation on the success or failure of any amalgam restoration is undisputed. Gabel 76 stated:

Due to the inherent characteristic of amalgam and certain peculiarities of the deciduous molars failures of the amalgam restoration are more frequent than any other type.

Ireland, 77 in 1947 , outlines the most common errors in cavity preparation of Class II deciduous molars. He stated that the most common errors were too narrow buccolingual preparations at the occlusal isthmus, inadequate preparation of the occlusal step, and extreme 
tapering toward the buccal and lingual of the proximal walls.

The occlusal portion of Class II cavity preparations in deciduous molars has occupied the interest of many investigators. Brown 78, 79 offered a mechanical basis for the preparation of Class II cavity preparations in deciduous molars. He stated that the occlusal dovetail should be shallow and broad, with rounded contours. The floor of the occlusal step should be flat and form the base of a truncated cone. Sweet 80 stated that cavity preparations in deciduous teeth should be governed by the morphology of the teeth, the type of filling material to be used, esthetics, and economics. He also advocated a wide occlusal isthmus that was slightly undercut. The buccal and lingual walls of the occlusal step should be paraliel to the external buccal and lingual surfaces.

Noonan, 81 in 1949 , conducted a study applying photoelasticity to research on cavity preparations. He concluded that a flat floor with rounded line angles and rounded retention points permitted less stress concentration than sharp angles and sharp retention points. Lampshire, 82 in 1950 , conducted an investigation to test and evaluate various CIass II cavity forms to determine the most beneficial prinicples of cavity preparation. His results indicated that the greatest resistance to 
fracture is achieved by a wide occlusal isthmus and a rounded pulpal floor. Lampshire 83 also stated that the preparation should be based entirely on dentin, penetrating at least one millimeter into the dentin without fear of pulpal exposure. He proposed that the width of the occlusal isthmus should be one-fourth the buccolingual dimension of the tooth. Best 84 later advocated the same principles as Lampshire.

Fartsook 85 stated that the two main factors in the preparation are resistance and retention form. He differed with Lampshire in the width of the occlusal isthmus by proposing that the width be one-half the intercuspal dimension of the tooth.

Castaldi 86 also advocated a wide occlusal isthmus and a rounded pulpal floor. Mahler 87 stated that one of the main retentive features of a Class II cavity preparation in deciduous molars should be an undercut occlusal dovetail.

Ireland 88, 89,90,91 outlined a detailed procedure for cavity preparation in primary teeth. He stressed a dovetailed occlusal outline composed of arcs, circles, and gently rounded curves that include all pits, fissures, grooves, and carious areas. The cavosurface areas of the occlusal step should be placed in non-stress.areas with no bevels. The side walls of the occiusal should be parallel or 
converge slightly as they approach the cavosurface margin.

McDonald 92 discussed some basic principles in the preparation of cavities in deciduous teeth. He stated that the cavity preparation should extend into all pits and fissures and should include all areas of carious involvement. MicDonald advocated a wide occlusal isthmus buccolingually, the optimum average width being approximately one-half the intercuspal dimension of the tooth. The occlusal floor should be flat, and the depth should be approximately onehalf milimeter pulpally from the dentinoenamel junction. He also stated that the internal line angles should be rounded to reduce stress concentration and permit more complete condensation in these areas.

The proximal portion of Class II cavity preparations in deciduous molars has frequently been designated as a major area of restorative failures. As stated previously, Ireland 77 proposed that extreme tapering toward the buccal and lingual of the proximal walls was a common error in cavity preparation. Brown 78,79 stressed a triangularshaped proximal box whose base was the gingival floor. He stated that the gingival proximal line angles should be gently rounded. The proximal walls should be parallel with some flaring for extension into free-cleansing 
areas. Sweet ${ }^{80}$ recommended that the buccal and lingual walls of the proximal box be parallel to the external buccal and lingual surfaces. Kelsten ${ }^{93}$ stressed the importance of preparing the proximal walls so that they were perpendicular to the enamel rods. Lampshire, 82,83 Best, 84 Castaldi, 86 Ireland, $88,89,90,91$ and McDonald 92 agreed with the previous investigators by advocating that the buccal and lingual walls of the proximal box should flare enough to carry the margins into free-cleansing areas and should reach a cavosurface angle of 90 degrees.

As stated previously, Noonan 81 concluded in his studies that rounded line angles and rounded retention points permitted less stress concentration than sharp angles and sharp retention points. Based largely on Noonan's work, other investigators $78-80,82-86,88-95$ have advocated rounded pulpoaxial line angles and rounded buccogingival and linguogingival line angles. The reasons for rounding all line angles are to permit less stress concentration and more facilitation in condensation.

Ireland 94,95 advocated a U-shaped groove at the gingivoaxial line angle as an aid in retention of the amalgam restoration. Other investigators $78,79,86,87,92,93$ advocated side retention grooves in the buccoaxial and linguoaxial line angles. These grooves should 
extend from the gingival floor occlusally to the dentinoenamel junction. Lampshire 82,83 and Best 84 stated that retention grooves could be included in the preparation, but were not very important as either an aid in retention or an aid in reduction of flow.

\section{Television Instrumentation}

Klein, 96 in 1963, described the use of the television microscope in dental research. He observed that intraoral clinical investigations at high magnifications were difficult because of cumbersome equipment and the low light levels in the oral cavity. He stated that these limitations made it imperative that new methods of instrumentation be developed for both clinical and laboratory use.

Klein designed the television microscope to meet the problems implicit to the small size and low light level of the oral cavity by magnifying the image of the operating microscope fourfold and adjusting the lightness and brightness of the television image electronically. These modifications made observation and measurement of deterioration at the margins of dental restorations possible.

Klein and MacPherson 97,98 designed and developed the instrumentation for television microscopic viewing and measurement of cavosurface margin deterioration of restorations 
in primary teeth. This instrumentation was achieved by coupling a petrographic microscope to a two-camera closed circuit television system through scan line measurement circuitry. A one millimeter area of the cavosurface margin can be serially viewed at $250 \mathrm{X}$ magnification with linear measurement changes as small as two microns being noted. 
STATEMENT OF PROBLEM 
The purpose of this study was to demonstrate the clinical application of the television microscope for direct intraoral micromeasurement of cavity margin deterioration. This was accomplished by measuring the marginal deterioration of proximal occlusal alloy restorations in deciduous second molars. The margins were evaluated on the basis of the character, the extent, and the nature of the margin deterioration. 
EXPERIMENTAL PROCEDURES 
The experimental procedures section of this thesis has been divided into four parts, as follow s:

1. Clinical operative procedures: The criteria for selection of teeth, cavity preparation, base and restorative materials utilized, restoration placement, and impression technique for the gold overlay,

2. Laboratory procedures: A description of the fabrication and design of the proximal occlusal gold overlay,

3. Television microscopy evaluation:

The procedures for postoperative polishing and the television microscopy evaluation at one week, two weeks, four weeks, 12 weeks, $24 \mathrm{weeks}$, and $36 \mathrm{weeks}$ after insertion, and

4. Television instrumentation: The design and development as desçribed by KIein and MacPherson. 97,98

\section{Clinical Operative Procedures}

The teeth selected for this study werefrom children in the mixed dentition stage selected from the patients receiving treatment in the Pedodontic Department at Indiana University School of Dentistry. The sample was.limited to the maxillary arch because of greater 
stability and ease of television microscopic photography. The teeth selected for this study were second deciduous molars with incipient to moderate mesial caries with adjacent and opposing teeth in occlusion and with sufficient clinical crowns to permit isolation with the rubber dam (Figure la).

All of the clinical operative procedures were standardized on a Columbia Dentoform prior to the beginning of the study. A mesiocclusal cavity preparation was prepared in a maxillary second deciduous molar in the dentoform. A pre-formed stainless steel matrix band was then adapted around the tooth to reproduce the proximal contour. The matrix band was wedged at the cervical margin, and the tooth was restored with silver amalgam alloy. The restoration was polished 24 hours after insertion. The mesiobuccal margin was then viewed on the television microscope, and the marginal adaptation was measured. In this manner standardization of cavity preparation, condensation procedures, and marginal adaptation was accomplished.

The deciduous teeth were anesthetized by infiltration in the maxilla with approximately $1.7 \mathrm{cc}$. of a two percent anesthetic solution, Xylocaine Hydrochloride, with 1:100,000 epinephrine. A mesiocclusal cavity was prepared with an air-turbine as described by 
McDonald.92 A number 557 carbide bur was used to outline the occlusal step. The cavity preparation was extended pulpally to a depth of approximately one-half millimeter below the dentinoenamel junction. It was extended on the occlusal to include all pits and fissures. The heavy, transverse ridge of the maxillary second deciduous molar was not crossed unless undermined by caries. The pulpal floor was flat, but the angle formed by the pulpal floor and the axial walls was gently rounded to reduce stress concentration. The buccolingual width of the occlusal isthmus was approximately one-half the intercuspal dimension of the tooth. An occlusal dovetail was prepared so that its buccolingual width was slightly greater than the isthmus width. The bur was used in a pendulum-swinging action to prepare the proximal box and to establish the depth of the gingival seat. The gingival seat was established just beneath the free margin of the gingival tissue. The axial wall was extended just beneath the dentinoenamel junction. The buccal and lingual proximal walls converged slightly toward the occlusal and extended into a free-cleansing area. The mesiobuccal proximal wall was extended just beyond minimal extensions to provide adequate access for television viewing (Figure $1 b$ ). A plastic model, duplicating the exact width of the television microscope light beam, was then 
placed at the mesiobuccal wall to determine if the extension was sufficient for television viewing (Figure lc). The cavosurface angles were prepared at 90 degrees. All angles with the exception of the cavosurface angles were slightly rounded. The cavity preparation was then refined with a number 557 bur in a slow-speed handpiece and smoothed with hand chisels and enamel hatchets. A thin layer of a calcium hydroxide base, Caulk Dycal, was placed over the pulpal and axiopulpal walls.

Unitek pre-formed, stainless steel matrix bands were contoured and wedged at the cervical margin. The alloy, Baker Aristaloy, was mixed at a 1:1 ratio of alloy to mercury for 45 seconds with a Wig-L-Bug mechanical amalgamator. The filling material was inserted and packed by hand condensation, using small amalgam pluggers in the proximal box and graduating to large amalgam pluggers until overpacked for carving. The matrix was withdrawn and the excess amalgam on the proximal walls was removed with an explorer. Using a stock plastic tray, an impression of the restored tooth was taken immediately after carving with Kerr Permlastic Heavy Body Rubber Base. The patient was then reappointed one week later for polishing the restoration and television evaluation (Figure ld). 


\section{Laboratory Procedures}

The rubber base impression was boxed with yellow beeswax and poured with Cristobalite inlay investment material with a water/powder ratio of $19 \mathrm{cc} .50 \mathrm{gm}$. The impression was poured a second time using yellow stone which served as a finishing model for the overlay. The investment model was allowed to dry and the mesiobuccal proximal margin of the restoration was carefully outlined with a sharp pencil. The model was placed on a Ney surveyor so that the marking arm was perpendicular to the mesiobuccal margin of the restoration (Figure $1 \mathrm{e}$ ). A piece of thin transparent, 22 gauge Kinco adhesive casting wax was adapted over the mesial half of the occlusal portion of the restored tooth and over the distal half of the occlusal portion of the adjacent tooth, with an extension over the interproximal portions of the restoration and the adjacent tooth from buccal to lingual. The outlines mesiobuccal margin of the restoration could be seen through the wax (Figure If).

A plastic model, duplicating the exact width of the television light beam, was fabricated with a hole through its longitudinal center to replace the surveyor arm. A piece of .060 stainless steel tubing was fabricated with an internal soldered spring that held a 
piece of pencil carbon, Sheaffer's Fineline Pencil Carbon, the diameter of a number 557 bur. The modified surveyor arm was returned to the surveyor along with the waxed investment model. The carbon point was heated slightly over a gas burner, and the surveyor arm was lowered so that the carbon point melted through the wax in the area of the gingival one-third of the pencil outline of the mesiobuccal proximal margin of the restoration, observed through the transparent wax. The carbon point was allowed to cool, the spring was disengaged, and the surveyor arm was raised. This left the carbon point in place in the waxed pattern on the model. A second carbon point was then inserted in the area of the occlusal one-third of the mesiobuccal proximal margin of the restoration in a like manner (Figure lg). The investment model was trimmed, sprued on the occlusal surface, invested, placed in a "burn out" oven for one hour at $1250^{\circ} \mathrm{F}$., and cast in Ney-ORO B-2 inlay gold. The cast overlay was fitted on the yellow stone model; the sprue was removed; and the carbon points were punched out. The mesiobuccal proximal margin of the restoration could then be microscopically viewed, repeatedly, through the two openings which were placed perpendicular to the ninety degree cavosurface margin. 
Television Microscopy Evaluation Procedure

One week after the insertion of the restoration, the tooth was isolated with a rubber dam, the proximal surfaces were finished with an extrafine sandpaper disc, and the occlusal surface was refined with dull, round finishing burs. The restoration was polished with moist flour of pumice, using a rubber cup, followed by a tin oxide agent. The cast overlay was then placed over the restored tooth for television evaluation of the restoration (Figure $1 \mathrm{~h}$ ).

The mesiobuccal proximal margin of the restoration was observed by the television microscope through the occlusal and gingival marginal observation holes at $250 x$ magnification (Figure 2). The image that appears on the storage master monitor was made up of 525 lines of scan. An oscilloscope introduced into the circuit made it possible to select any one line of scan for measurement. A micron dot scale was then electronically placed on the scan line, and the area of marginal deterioration was measured and recorded. Two measurements of marginal deterioration were noted at each appointment. One measurement was made through the hole in the occlusal one-third of the overlay and one through the hole in the gingival one-third. A photograph, for recording purposes, was then made of 
each of the images from the master monitor. These measurements were taken at one week, two weeks, four weeks, 12 weeks, 24 weeks, and 36 weeks after insertion of the amalgam restoration (Figure 3 ). The areas to be measured were oriented by the holes in the cast overlay and by visual identification of landmarks on the tooth and restoration as seen on the television monitor.

\section{Television Instrumentation}

The television microscope instrumentation was designed and developed by Klein and MacPherson. 97,98 The following is a brief explanation of the design of the instrumentation as described and illustrated in their papers. A schematic block diagram of the instrumentation is noted in Figure 4. Microscopic System. The optical system was a Leitz petrographic microscope consisting of a monocular tube mounted on a detachable microscope limb with dual rack and pinion and micrometer fine focusing. The objective system housed a fixed ring mirror and an interchangeable objective with an adjustable ring condenser. The ring condenser surrounded the objective concentrically and guided the light reflected from the ring mirror to the object. The objective had a free working distance of $16 \mathrm{~mm}$. This working distance 
made it possible to examine and measure deeper margins of the specimen which would not be possible with standard micro-objectives. The eyepiece, a Huygens6x, was mounted in an attachment that consisted of a lateral focusing telescope ( $10 x$ ) that indicated the area being viewed. The eyepiece and telescope were coupled to the television viewing camera through a light-tight adapter tube. A self-winding central flash synchronized shutter was operated at a $1 / 125$ second setting to activate the permachon storage camera. A release for activating the prism and the shutter was driven, in correct sequence, by an electro-solenoid unit that was energized by a foot control switch at the time of exposure (Figure 5).

Light System Design. A light housing was designed which combined the light requirements of the vidicon pickup tube, used for focusing and observation, and the permachon storage tube. A 100-watt mercury arc lamp, with a forced air cooling system, servedthe vidicon observation system through a light beam splitter that utilized a dichroic coating which reflected $4600 \AA$ Iight, for maximum response of the permachon storage tube. An electronic flash power supply with variable light output was used because of variations of light reflectance and absorption from tooth to tooth. Television Camera. A camera chain with a 
standard $7735 \mathrm{~A}$ vidicon pickup tube was used as the focus viewing camera and an identical camera chain was modified to accomodate a permachon storage tube.

Operation. During the operation of the microscope, the viewing camera was used to allow the operator to focus the area to be measured, while adjusting the camera-microscope position. A n eight-inch television monitor, located near the microscope area, was used to allow the operator to view the image. The area to be studied was brought into focus through the viewing monitor. The permachon storage tube was activated by the shutter foot control which fired the electronic flash tube, momentarily exposing the permachon tube to the viewed image for storage and measurement (Figure 6). Measurement System. The measurement system enabled the operator to select, identify, and illuminate any one of the 525 lines of scan of the television image and generate marker dots that identified the area of linear measurement for recording purposes. The dots could be moved by a vernier control along the identified and illuminated line containing one thousand divisions.

The calibration of the instrumentation was accomplished by focusing the microscope assembly on a glass stage micrometer slide ruled $0.01 \mathrm{~mm}$. The micrometer image was centered and focused with the vidicon viewing 
camera, and a storage picture was made with the permachon camera. The image positioning was calibrated, using the video mixer-switcher for adding the stored image and the viewing image into one composite image. The viewing image was then removed, leaving the stored image on the monitor. The line selector was positioned through the micrometer ruling with marker dots superimposed over the ruling. The spacing between the marker dots was noted and adjusted so that each dot appeared over each $0.01 \mathrm{~mm}$. marking. The calibration of the vernier control, which positioned the markers along the selected line, was adjusted. so that one dial division was equal to $0.002 \mathrm{~mm}$. Recording Photography. After completing the measurement procedure, the monitor display of the stored image with the calibrated marker dots identifying the area of measurement was photographed for recording purposes. A camera holding device (Figure 7) designed to move along the console on a track made it possible to position the camera at any monitor in the console. A positive print was provided in 20 seconds with a negative available for making additional prints or enlargements. 
DATA 
The data presented here consists of the average gingival and occlusal measurements of marginal deterioration for the total sample during the time periods of one week, two weeks, four weeks, 12 weeks, 24 weeks, and 36 weeks. Figure 8 compares the average gingival and occlusal measurements of marginal deterioration for the total sample, consisting of 51 restored second deciduous molars, plotted against time in weeks. The gingival marginal deterioration ranged from 4.9 microns at one week to $37.8 \mathrm{microns}$ at $36 \mathrm{weeks}$. The occlusal marginal deterioration ranged from 5.4 microns at one week to 60.1 microns at 36 weeks.

The average gingival and occlusal marginal deterioration is demonstrated by a bar graph in Figure 9. The data is presented relative to the change between the indicated measurement periods. This data is presented as the average micron change and the percent deterioration of the total marginal deterioration.

The average gingival marginal deterioration measured 4.9 microns at one week, 7.5 microns at two weeks, 11.5 microns at four weeks, 21.4 microns at 12 weeks, 24.2 microns at 24 weeks, and 37.8 microns at 36 weeks.

The average occlusal marginal deterioration measured 5.4 microns at one week, 7.4 microns 
at two weeks, 14.3 microns at four weeks, 20.8 microns at 12 weeks, 42.5 microns at $24 \mathrm{weeks}$, and $60.1 \mathrm{microns}$ at $36 \mathrm{weeks}$.

The percent gingival deterioration change increased from 8.2 (2.7 microns) at 1 to 2 weeks to 11.9 ( 3.9 microns) at 2 to 4 weeks. At 4 to 12 weeks, this percent deterioration increased to 30.1 ( 9.9 microns). The percent gingival deterioration then decreased to 8.5 ( $2.8 \mathrm{microns}$ ) at 12 to 24 weeks and increased to 41.3 ( $13.6 \mathrm{microns})$ at 24 to 36 weeks.

The percent occlusal deterioration change increased from 3.7 ( 2.0 microns) at 1 to 2 weeks to 12.6 ( 6.9 microns) at 2 to 4 weeks. At 4 to 12 weeks, this percent deterioration decreased to 11.9 ( 6.5 microns). The percent occlusal deterioration then increased sharply to 39.7 ( $21.7 \mathrm{microns}$ ) at 12 to 24 weeks and $r e$ mained at near this level at 32.2 ( 17.6 microns) for the 24 to 36 week time period. 
ILLUSTRATIONS 
Figure 1. Clinical and laboratory procedure for the television microscope. A preoperative view of a maxillary second deciduous molar selected for this study (a) with typical preparation at (b). A plastic model ( $\mathrm{x}$ ) duplicating the three dimensions of the television microscope light beam at (c) was utilized to determine the mesiobuccal margin extension suitable for television viewing. (d) The complete polished restoration. (e) The investment model of the restored tooth, in a modified dental surveyor, with the mesiobuccal outlined. (f) Waxup of the gold overlay and placement of the carbon points perpendicular to the margin in the wax pattern. (g) Completed waxup with carbon points for the preparation of the gingival and occlusal viewing hole. (h) The cast gold overlay seated in the mouth with the gingival and occlusal viewing holes overlying and perpendicular to the mesiobuccal proximal margin of the restoration. Through these holes this margin can be repeatedly viewed and measured, at 250 times magnification, by the intraoral television microscope. 


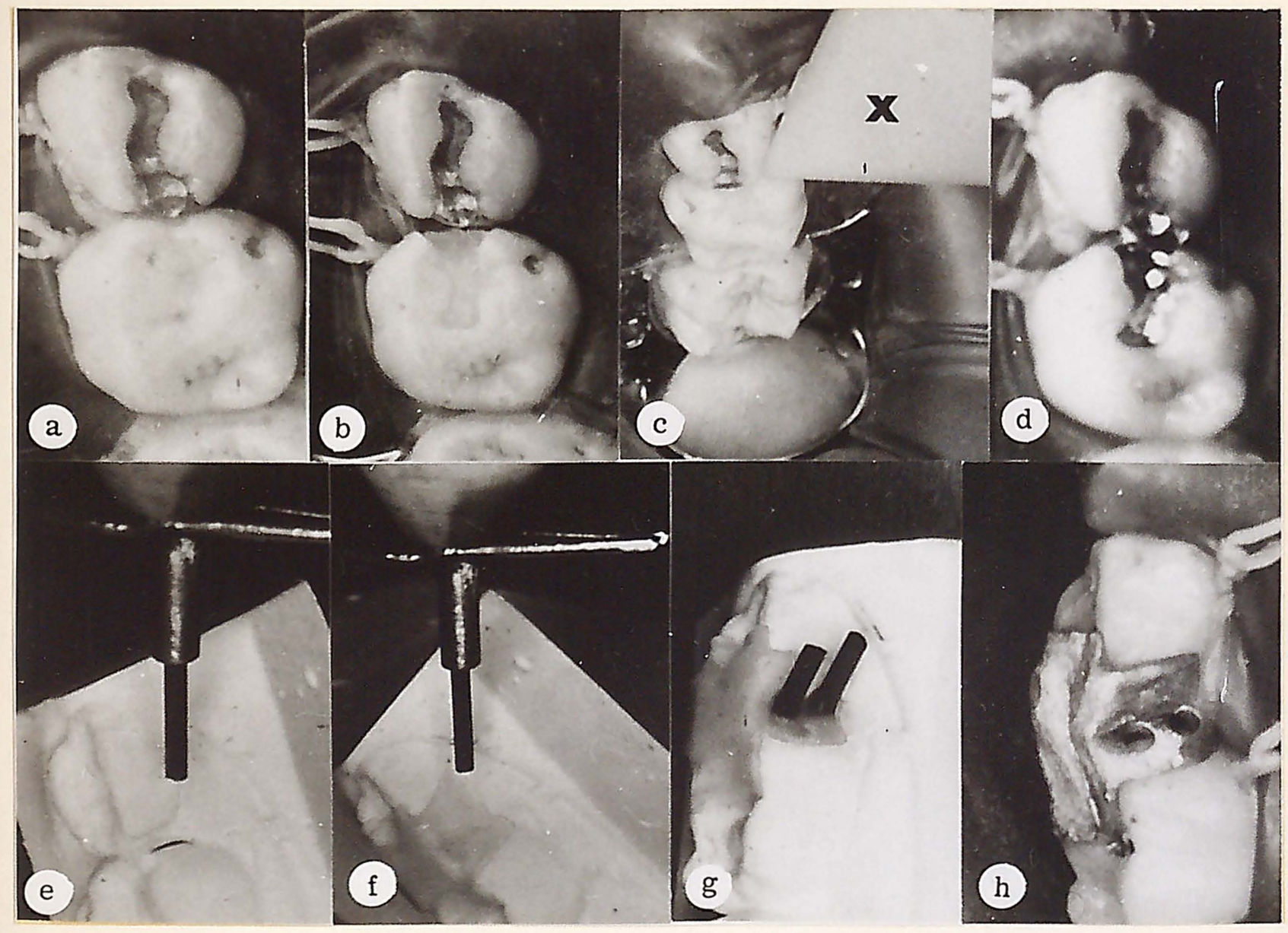


Figure 2. Cast gold overlay. The photograph demonstrates the cast gold overlay with viewing holes at (A). 


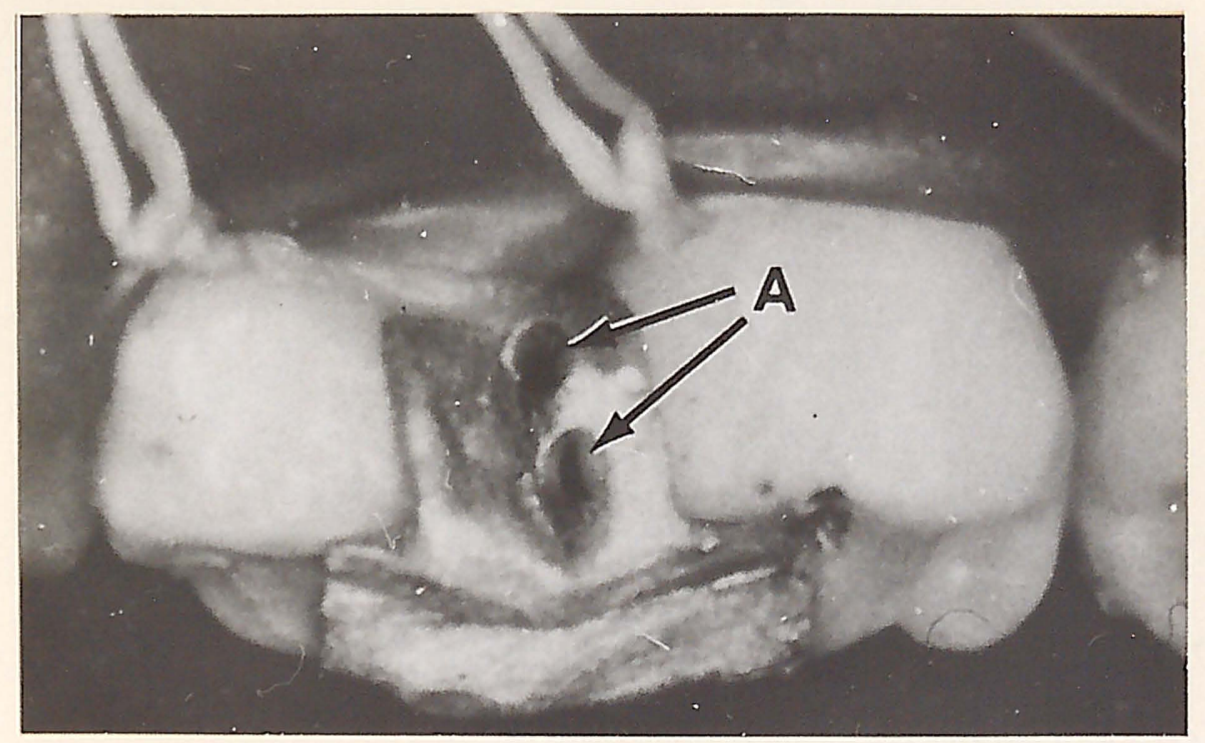


$-46-$

Figure 3. The serial television gingival micromeasurement (original magnification 250X) photographs indicate the line of measurement as a series of dots, calibrated to be ten microns apart. 


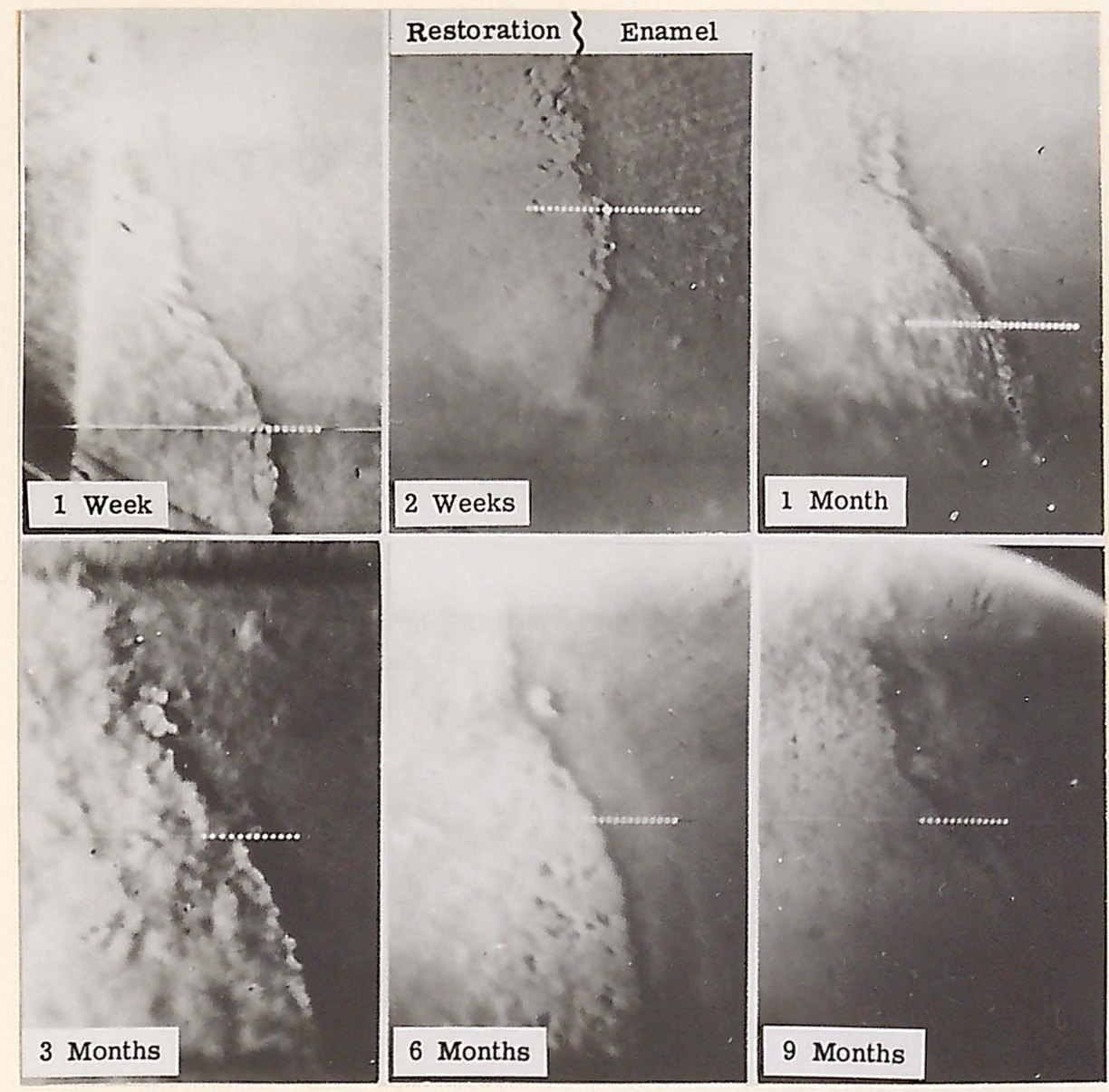


Figure 4. Intraoral microscope system. This schematic block diagram illustrates the application and basic components of the intraoral television micromeasurement instrumentation. The microscope views the restored margin of the tooth whose image is monitored by the viewing camera. The permachon camera is activated through the foot controlled shutter light system, to store the viewed image. Electronic micromeasurement of the restored tooth margin adaptation is accomplished through the measurement instrumentation composed of a line selector, marker generator, oscilloscope, special effects generator, and video mixer switcher. 


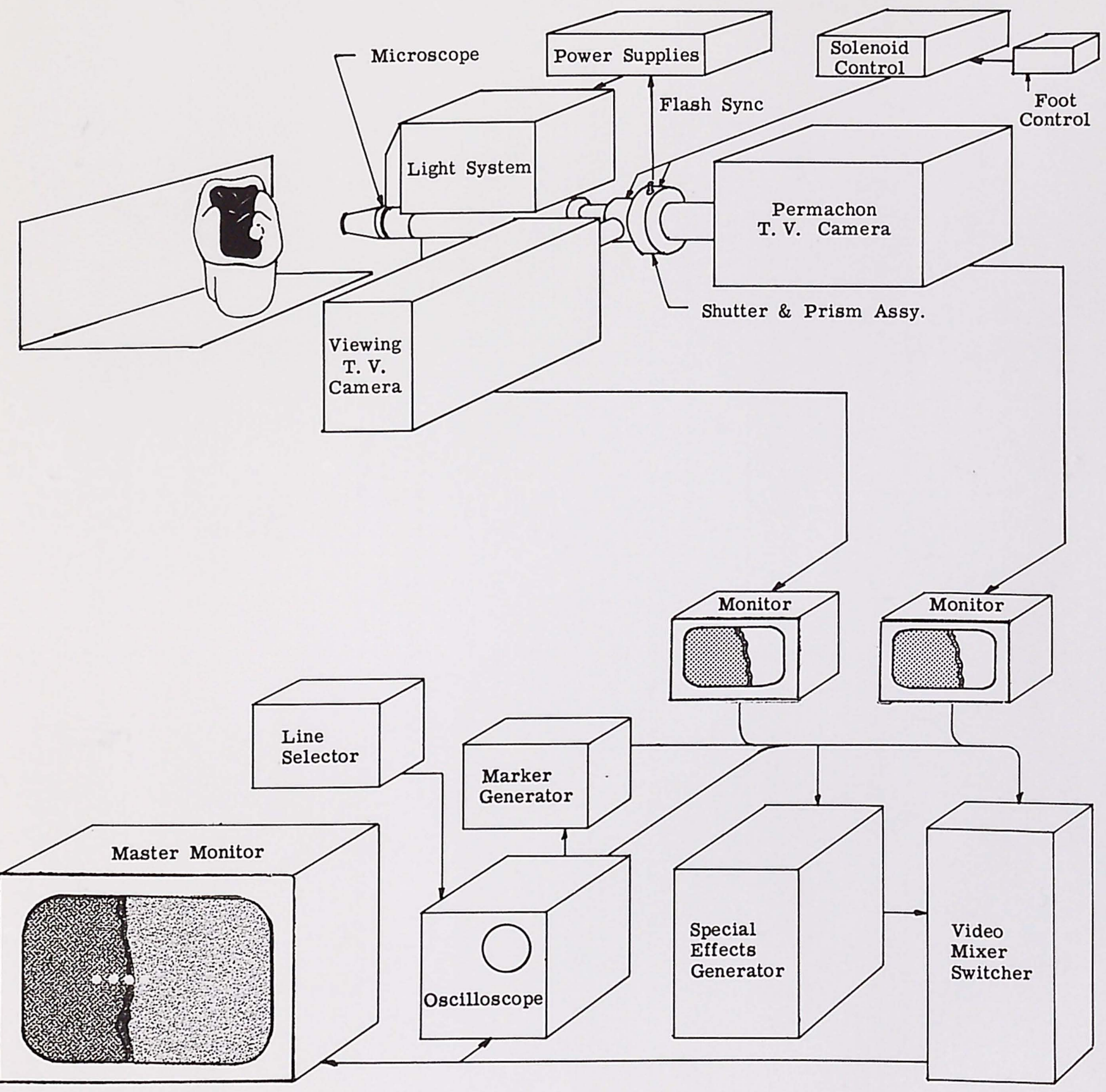


$-48-$

Figure 5. A labeled detail photograph of the intraoral microscope assembly. 


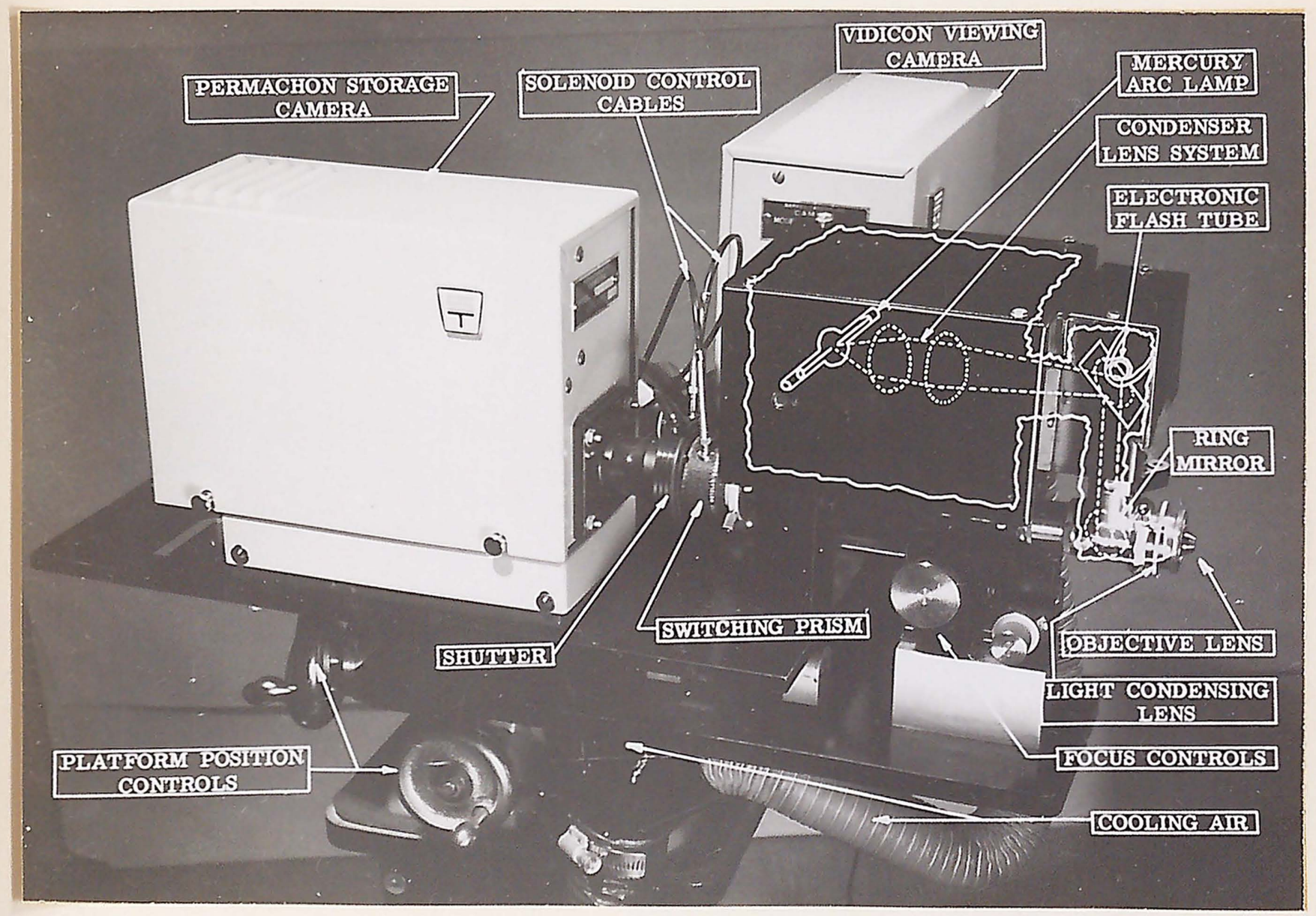


Figure 6. The intraoral television microscope clinically viewing the mesiobuccal margin of the second deciduous molar is noted above. A closeup photograph, demonstrating the relationship of the objective lens of the microscope to the gold overlay as it is focused through the viewing holes for marginal deterioration measurement, is illustrated below. 

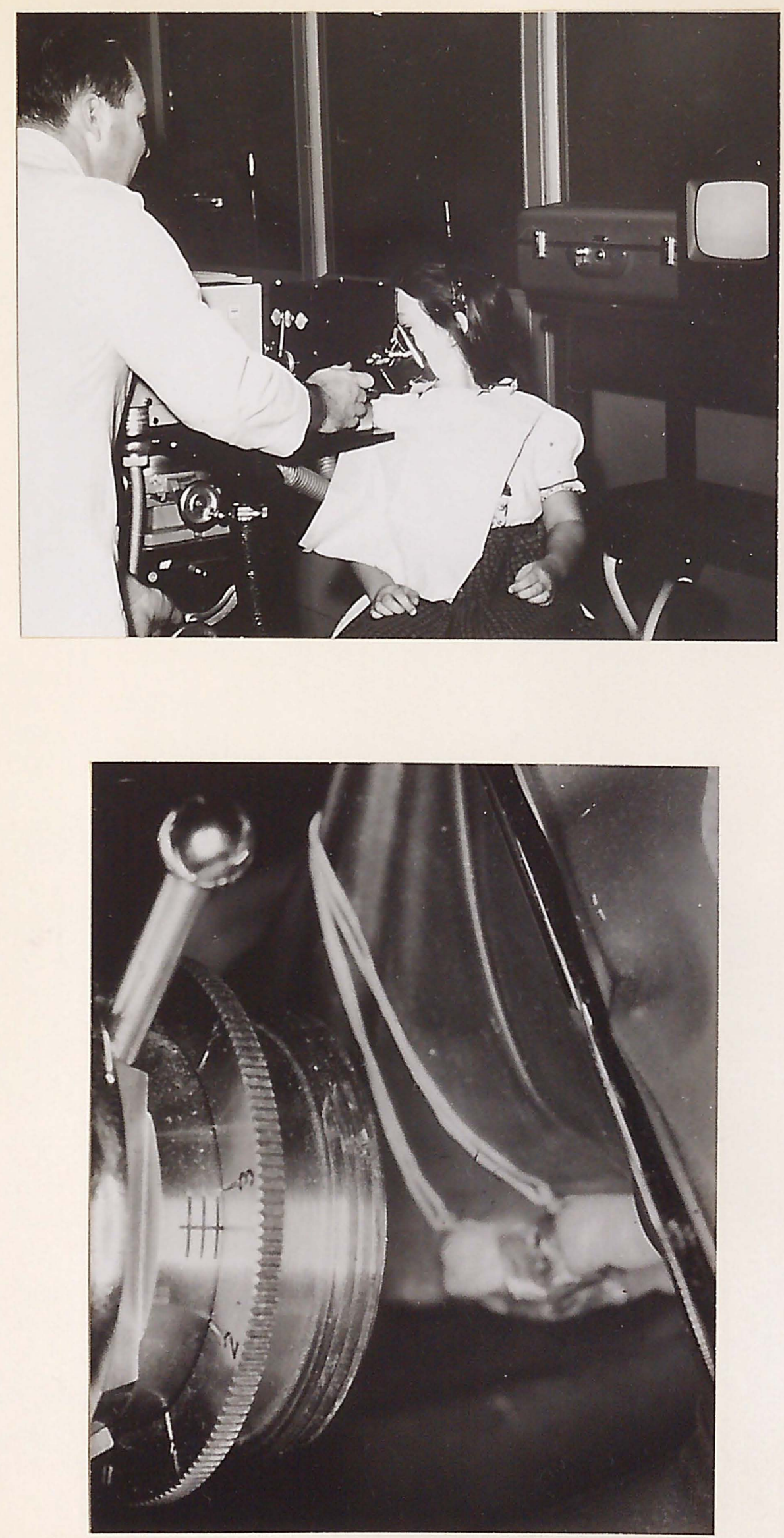
Figure 7. An overall view of the laboratory with intraoral microscope at (A) and the camera holding device at $(B)$. 


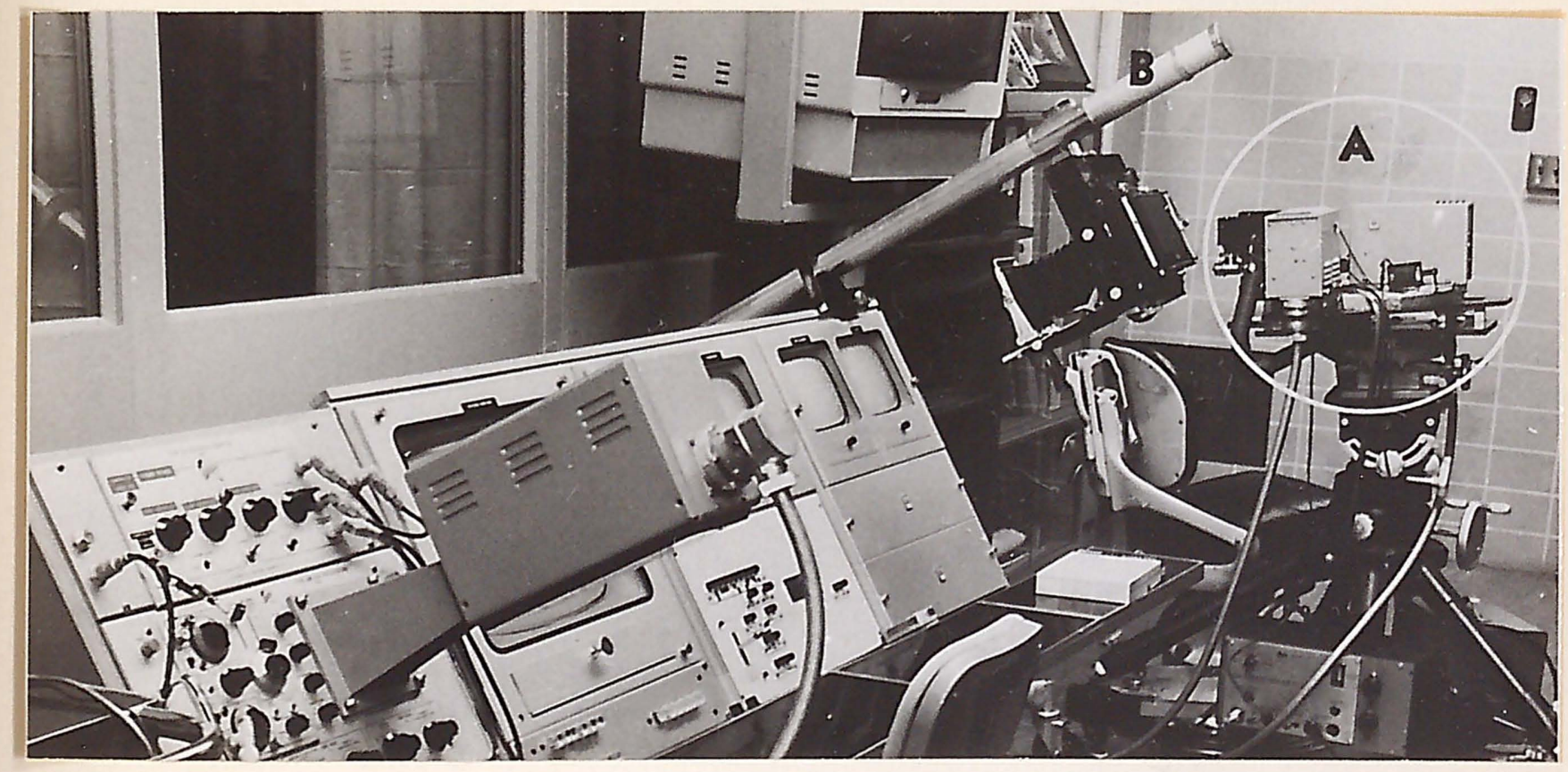


AVERAGE MARGINAL DETERIORATION

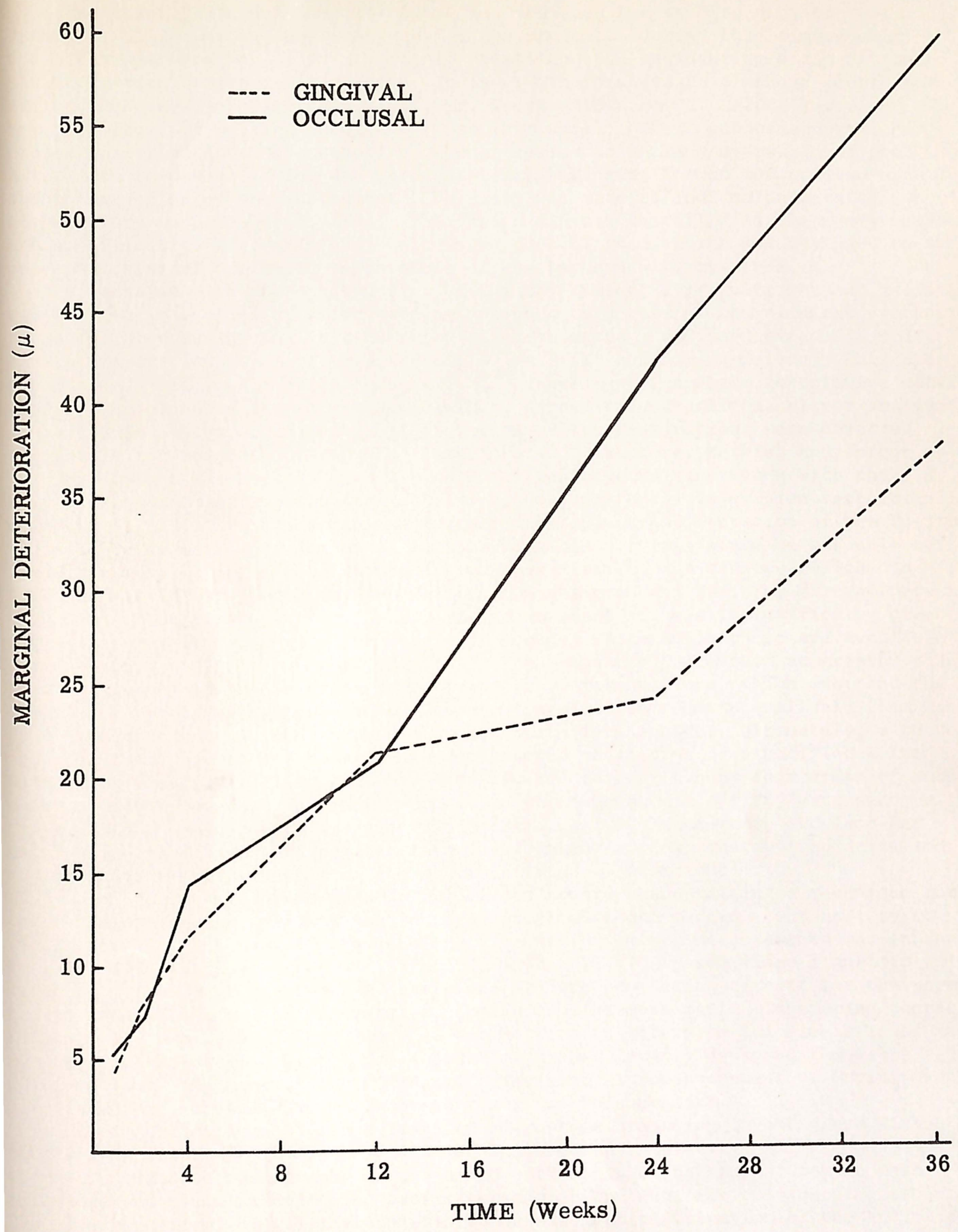

FIGURE 8 
AVERAGE MICRON \& PERCENT MARGINAL DETERIORATION

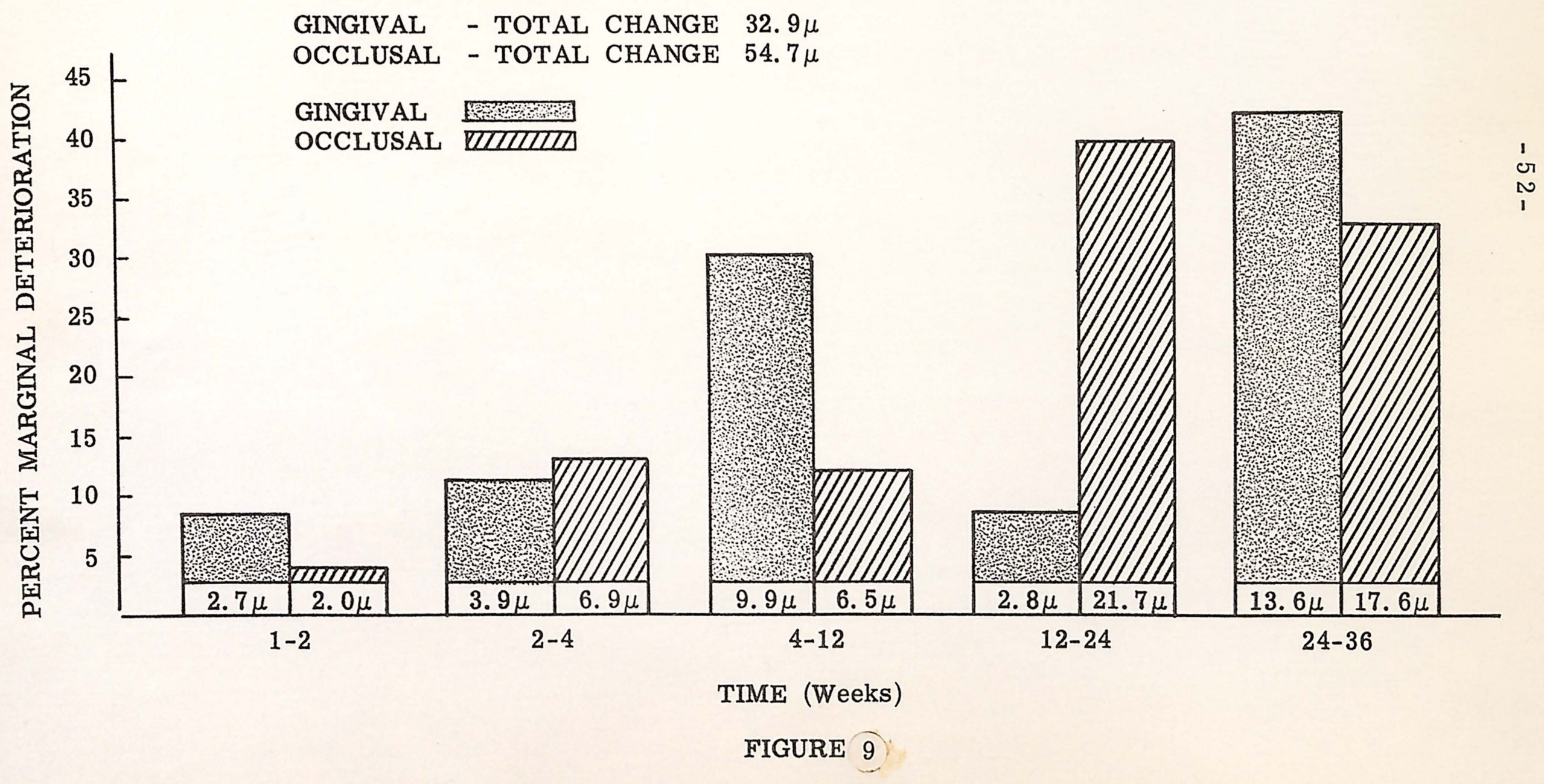


Figure 10. Intraoral television micromeasurement. The area of interest in the illustrated serial television micromeasurement occlusal hole photographs (original magnification 250X) is outlined within the white box. (A) denoted the amalgam restoration with (E) denoting the enamel of the tooth. The line of marginal micromeasurement is indicated by the line of white dots through the restoration margin. The space between each of these dots is calibrated to be ten microns. The arrow indicated an area of marginal breakdown, beginning at two weeks with complete loss at nine months. The dashed line denotes the gradual fracture of the occlusal mesiobuccal proximal margin, beginning at one month and becoming clinically evident at nine months. 


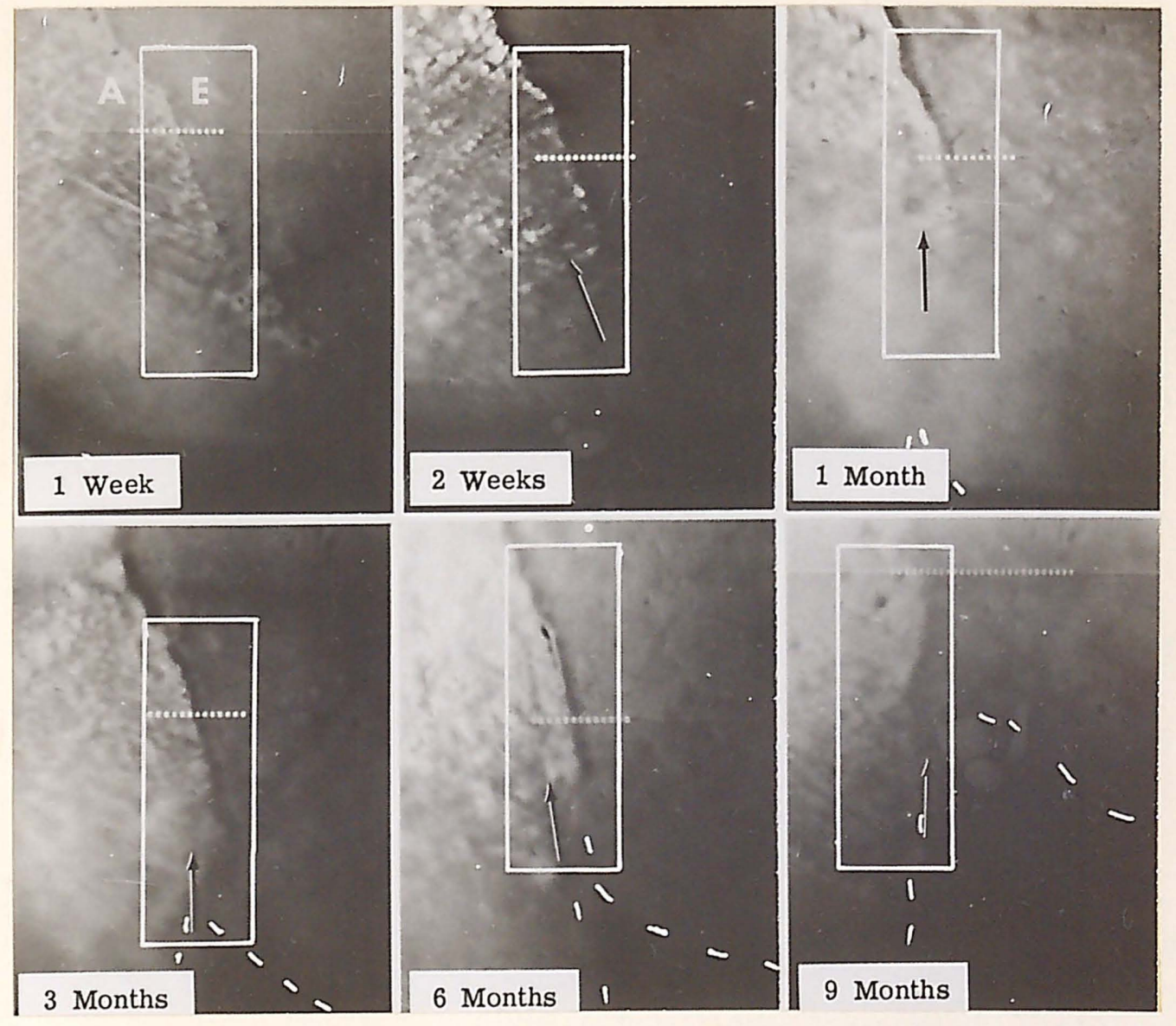


DISCUSSION 
The objectives of this study were to demonstrate the clinical use of the television microscope as a tool for dental research and to measure and assess the marginal deterioration of proximal occlusal alloy restorations in deciduous second molars.

The proximal margin was observed through the television microscope at intervals of one week, two weeks, four weeks, 12 weeks, 24 weeks, and 36 weeks postoperatively. This margin was observed in two areas, the gingival onethird and the occlusal one-third. The proximal margin was chosen because this is the area where previous investigators have frequently observed marginal deterioration on a clinical basis. $9,49-51,56-58,62,64,74$ It was found that the mesiobuccal margin provided readilyavailable access for viewing with the television microscope; therefore, only mesiocclusal alloy restorations were chosen for this study. The extent of the decay governed the extent of the preparation. Incipient to moderate decay was selected so that the possibilities of pulp therapy and large alloy restorations were eliminated as variable factors in the study. Two random sample areas of the proximal margin were chosen for observation, one area midway in the gingival one-third of the proximal 
margin and another area midway in the occlusal one-third.

The gingival area of the proximal margin deteriorated at a faster rate during the first 12 weeks than the occlusal area. The gingival deterioration for the total sample was $50.2 \%$ of the total gingival marginal deterioration during the first 12 weeks. The occlusal marginal deterioration data demonstrated that $71.9 \%$ of the total occlusal deterioration occurred in the last 24 weeks of the study.

During the evaluation of the serial photographic records, it was noted that in all probability the measured marginal deterioration in the gingival area was initiated by microscopic alloy flash. This flash initially broke or chipped away, leaving microscopic areas of unsupported enamel which eventually broke down an additional amount probably due to occlusal and masticatory forces, leaving areas of unsupported marginal alloy. The process of the alloy chipping followed by subsequent enamel breakdown created a repetitive cycle of continuing deterioration. An evaluation of the serial photographic records indicated that marginal alloy flash appeared more frequently in the gingival portion of the proximal margin than in the occlusal portion (Figure 10). This fact could account for the greater percentage of marginal deterioration during the first three months than in the occlusal portion. 
There are two possible explanations for the increased microscopic alloy flash in the gingival one-third of the proximal margin. It is more difficult to prepare, condense, and finish proximal occlusal alloy restorations in the gingival one-third of the proximal margin than in the occlusal one-third. This fact is related to problems of operator and instrument access in this area. Restricted access promotes uneven margins, incomplete condensation, and inadequate polishing of the restoration. A second possible explanation for increased flash is that excess amalgam on the proximal margin was removed with an explorer; therefore, a burnishing effect could have taken place, producing a mercury-rich margin. This margin would, therefore, be more vulnerable to fracture and corrosion. More excess amalgam may have been present in the gingival area of the proximal margin than in the occlusal area because of inadequate adaptation of the matrix band in this area and failure of the matrix band to adequately resist forces of condensation.

The following factors could introduce some error in the study. The entire proximal margin was not evaluated and measured, but rather two specific areas were chosen in order to be able to make serial measurements. Intraoral instrumentation is being developed 
which will allow the investigator to study and measure the entire margin serially. Plaque and debris formation sometimes made measurements difficult, as the patients were not instructed in oral hygiene procedures. This decision was made so that a clear representation of what happened to an alloy restoration under the usual conditions observed in most children's mouths could be ascertained. In addition, no rotary instruments were ever applied to the proximal margins after the initial polishing procedure for fear of changing the character of the deteriorating proximal margin. The existing plaque and debris, therefore, sometimes tended to partially obscure the margin and accounted for some degree of error in reorientation and interpretation. It would be interesting to determine the effect of oral hygiene on marginal deterioration. The microscopic expansion and contraction of the alloy restoration sometimes produced a shadow in the marginal area which made it difficult to determine as to what was shadow or marginal deterioration. Here again, instrumentation is being developed to overcome this problem. These sources of error tended to exist in equal degree in both the gingival and occlusal areas of measurement, therefore balancing each other out.

The results of this study indicate the need for a reevaluation of the Class II deciduous 
cavity preparation design. The influence of masticatory and occlusal stresses on the total marginal deterioration point to the need for a critical evaluation of both the cavity design and the restorative material used.

The significance of this study lies in the demonstration of the us e of the television microscope for clinical dental research. It would be beneficial if the results of this study were correlated with the ultimate fate of the restorations. This would require continued observation and micromeasurement of the restorations until such time as they failed or the teeth were exfoliated. 
SUMMARY AND CONCLUSIONS 
This study was designed to demonstrate a clinical application of the television microscope in dental research and to measure and assess the marginal deterioration of Class II silver amalgam alloy restorations in deciduous teeth.

The teeth included in this study were from children in the mixed dentition stage selected from the patients receiving treatment in the Pedodontic Department at Indiana University School of Dentistry. The observation teeth were limited to the maxillary arch because of greater ease in standardization and auplication of the television microscopic photography.

The teeth selected for this study were second deciduous molars with incipient mesial carious lesions with adjacent and opposing teeth in occlusion and with sufficient intact clinical crown to permit isolation with the rubber dam.

All of the clinical operative procedures were standardized on a Columbia Dentoform prior to the beginning of the study. A mesiocclusal cavity preparation was prepared in a maxillary second deciduous molar in the dentoform. A pre-formed stainless steel matrix band was then adapted around the 
tooth to reproduce the proximal contour. The matrix band was wedged at the cervical margin, and the tooth was restored with silver amalgam alloy. The restoration was polished 24 hours after insertion. The mesiobuccal margin was then viewed on the television microscope, and the marginal adaptation was measured. In this manner standardization of cavity preparation, condensation procedures, and marginal adaptation was accomplished.

Mesial occlusal amalgam alloy restorations were placed in 51 deciduous second molars. The teeth were anesthetized by infiltration in the maxilla with approximately $1.7 \mathrm{cc}$. of a two percent anesthetic solution, Xylocaine Hydrochloride, with 1:100,000 epinephrine. The teeth were isolated under a rubber dam; the cavity preparations were prepared with an air-turbine dental handpiece using a number 557 carbide bur. The cavity preparation consisted of an occlusal step that included all pits, fissures, and carious areas; the occlusal isthmus was approximately one-half the intercuspal dimension of the tooth. The cavity preparation was extended pulpally to a depth of approximately one-half millimeter below the dentinoenamel junction; the pulpal floor was flat, but the angle formed by the pulpal floor and the axial wall was gently rounded to reduce stress concentration. The gingival seat of the proximal box was estabished just beneath 
the dentinoenamel junction. The buccal and lingual walls converged slightly toward the occlusal and extended into a free-cleansing area. The mesiobuccal proximal wall was extended just beyond minimal ext'ensions to provide adequate access for television viewing. A pre-formed stainless steel matrix band was adapted around the prepared tooth so that the proximal contour of the tooth was reproduced. The matrix band was then wedged at the cervical margin, and the tooth was restored with silver amalgam alloy.

A cast gold overlay was prepared for each restoration with observation holes placed in two areas of the mesiobuccal margin, one in the gingival one-third and one in the occlusal one-third. One week after the insertion of the restoration the alloy was polished, and the cast gold overlay was placed over the restored tooth for microscopic television observation. The mesiobuccal margin of the restoration was observed through the occlusal and gingival observation holes at a magnification of $250 x$. The teeth were observed at one week, two weeks, four weeks, 12 weeks, 24 weeks, and 36 weeks postoperatively. The marginal deterioration was measured electronically at each observation appointment.

The average gingival marginal deterioration measured 4.9 microns at one week, 7.5 microns at two weeks, 11.5 microns at four 
weeks, 21.4 microns at 12 weeks, 24.2 microns at 24 weeks, and 37.8 microns at 36 weeks.

The average occlusal marginal deterioration measured 5.4 microns at one week, 7.4 microns at two weeks, 14.3 microns at four weeks, 20.8 microns at 12 weeks, 42.5 microns at 24 weeks, and 60.1 microns at 36 weeks. The data indicated that the gingival area of the proximal margin deteriorated at a faster rate during the first 12 weeks postoperatively than the occlusal area. The percent of the total gingival marginal deterioration during the first 12 weeks was 50.2 . During the last 24 weeks, the occlusal area deteriorated faster, the percent of the total occlusal marginal deterioration being 71.9 .

Microscopic alloy flash was more frequently observed in the gingival area of the proximal margin as compared to the occlusal area. This fact could account for the accelerated marginal deterioration of the gingival area during the first 12 weeks of the study as compared to the occlusal marginal deterioration. Occlusal and masticatory forces could account for the occlusal marginal deterioration during the last 24 weeks of the study.

Additional research is needed in order to correlate the findings of this study with the ultimate fate of the restored teeth. The influence of oral hygiene on marginal deteriora- 
tion of amalgam alloys is an area of research that should be thoroughly investigated.

The results of this study indicated the need for a re-evaluation of the Class II deciduous cavity preparation design which would make it possible to more adequately restore and finish the gingival portion of the proximal margin.

This study successfully demonstrated the application of the television microscope in clinical dental research. Nore refined instrumentation is currently being developed to overcome the difficulties encountered with respect to shadow. In addition, intraoral instrumentation is also being developed that will enable investigators to view entire margins rather than random areas. 


\section{REFERENCES}


1. Black, G. V.: The physical properties of the silver-tin amalgams. Dental Cosmos. $38: 882,1886$.

2. Gray, A. W.: Metallographic phenomena observed in amalgams. J. Amer. Dent. Ass. 6:513, 1919 .

3. Gray, A. W.: Metallographic phenomena observed in amalgams. J. Amer. Dent. Ass. 6:909, 1919.

4. Phillips, R. W. and Boyd, D. A.: Importance of the mercury alloy ratio to the amalgam filling. J. Amer. Dent. Ass. $34: 451,1947$.

5. Phillips, R. W. and Swartz, M. L.: Mercury analysis of one hundred amalgam restorations. J. Dent. Res. 28:569, 1949 .

6. Nadal, Rafael, Phillips, R. W., and Swartz, M. L.: Clinical investigation on the relation of mercury to the amalgam restoration: I. J.Amer. Dent. Ass. $63: 24,1961$.

7. Nadal, Rafael, Phillips, R. W., and Swartz, M. L.: Clinical investigation on the relation of mercury to the amalgam restoration: II. J. Amer. Dent. Ass. $63: 488,1961$.

8. Nadal, Rafael: Amalgam restoration: cavity preparation, condensing, and finishing. J. Amer. Dent. Ass. 65:66, 1962 .

9. Swartz, M. L. and Phillips, R. W.: Residual mercury content of amalgam restorations and its influence on compressive strength. J. Dent. Res. 35:458, 1956 . 
10. Wilson, R. T., Phillips, R. W., and Norman, R. D.: Influence of certain condensation procedures upon the mercury content of amalgam restorations. J. Dent. Res. $36: 458,1957$.

11. Wolcott, R. B.: Failures in dental amalgam. J. Amer. Dent. Ass. 56:479, 1958 .

12. Ward, M. L.: Modern tests for the strength of amalgam. J.Amer. Dent. Ass. $11: 487,1924$.

13. Phillips, R. W.: Compressive strength of amalgam as related to time. J. Dent. Res. $28: 348,1949$.

14. Taylor, N. O., Sweeney, W. T., Mahler, D. B., and Dinger, E. J.: The effects of variable factors on crushing strength of dental amalgams. J. Dent. Res. $28: 228,1949$.

15. Crowell, W. S. and Phillips, R. W.: Physical properties of amalgam as influenced by variations in surface area of the alloy particles. J. Dent. Res. $30: 845,1951$.

16. Ward, M. L. and Scott, E. O.: Further studies on the effect of variations in manipulations on dimensional changes and flow of amalgams. J. Amer. Dent. Ass. $22: 1164,1935$.

17. Skinner, E. W.: Research on the flow of amalgam. J.Amer. Dent. Ass. 25:1651, 1938 .

18. Sweeney, J. T.: Amalgam manipulation: manual vs. mechanical aids, Part II. J.Amer. Dent. Ass. 27:1940, 1940 .

19. Sweeney, J. T.: An imporved technic for packing and condensing uniform amalgam restorations by hand. J. Amer. Dent. Ass. $28: 1463,1941$. 
20. Phillips, R. W., Boyd, D. A., Healey, H. J., and Crawford, W. H.: Clinical observation on amalgams with known physical properties. J. Dent. Res. 22:167, 1943.

21. Phillips, R. W., Boyd, D. A., Healey, H. J., and Crawford, W. H.: Clinical observations on amalgams with known physical properties, final report. J. Amer. Dent. Ass. $32: 325,1945$.

22. Jarabak, J. R.: The effect of particle size on dimensional ch ange in dental amalgams. J. Amer. Dent. Ass. 29:593, 1942 .

23. Phillips, R. W.: Physical properties of amalgam as influenced by the mechanical amalgamator and pneumatic condenser. J. Amer. Dent. Ass. 31:1308, 1944.

24. Miller, C. E.: Construction of the amalgam restoration. J. Canad. Dent. Ass. $18: 119,1952$.

25. Ryge, Gunnar, Dickson, George, Smith, D. L., and Schoonover, I. C.: Dental amalgam: the effect of mechanical condensation on some physical properties. J. Amer. Dent. Ass. 45:269, 1952 .

26. Crawford, W. H. and Larson, J. H.: Dental restorative materials: amalgams, acrylics. J. Dent. Res. $33: 414,1954$.

27. Swartz, M. L. and Phillips, R. W.: A study of amalgam condensation procedures with emphasis on the residual mercury content of the increments. J. Dent. Res. $33: 12,1954$.

28. Sweeney, J. T.: Manipulation of amalgam to prevent distortion and corrosion. J. Amer. Dent. Ass. 31:375, 1944. 
29. Strader, K. H.: Amalgam alloy: its heat treatment, flow, mercury content and distribution of dimensional change. J. Amer. Dent. Ass. 38:602, 1949 .

30. Mosteller, J. H.: The principles of condensation of amalgam, J. Georgia Dent. Ass. 24:10, 1950 .

31. Eames, W. B.: Amalgam with a low mercury-alloy ratio. J. Amer. Dent. Ass. 58:78, 1959 .

32. Eames, W. B.: Effect of mercury/alloy ratio, condensation, and other variables on the adaptation of dental amalgam. J. Dent. Res.43:922, 1964. (Abst.)

33. Wolcott, R. B., Jendresen, M. D., and Ryge, Gunnar: Strength, dimensional change and adaptation of amalgam prepared with 1:1 ratio. Intern. Ass. Dent. Res. 41 st General Meeting. 40:95, 1962 .

34. Wolcott, R. B., Jendresen, M. D., and Ryge, Gunnar: Strength, dimensional change, and adaptation of amalgam prepared with 1:1 ratio. J. Amer. Dent. Ass. $67: 375,1963$.

35. Schoonover, I. C., Souder, Wilmer, and Beall, J. R.: Excessive expansion of dental amalgam. J. Amer. Dent. Ass. $29: 1825,1942$.

36. Miller, E. C.: Amalgam inconsistencies in its use in restorations. J. Amer. Dent. Ass. 33:349, 1946 .

37. Miller, E. C.: Clinical factors in the use of amalgam. J. Amer. Dent. Ass. $34: 820,1947$.

38. Miller, E. C.: Clinical procedures which effect amalgam restorations. Northwest Dent. 27:173, 1948 . 
39. Romnes, A. F.: Amalgam restorations: a critical survey of present day practice. Int. Dent. J. $4: 1,1953$.

40. Phillips, R. W.: Amalgam--its properties and manipulation. New York J. Dent. $23: 105,1953$.

41. McDonald, R. E. and Phillips, R. W.: Clinical observations on a contracting amalgam alloy. J. Dent. Res. 29:482, 1950 .

42. Mosteller, J. H.: An evaluation of the A.D.A. specification for amalgam alloy in relation to particle size. Ann. Dent. $12: 19,1953$.

43. Ottolengui, R.: The failures with amalgam as commonly used. Dental Cosmos. $67: 998,1925$.

44. Byrnes, R. R.: Why fillings fail. J. A mer. Dent. Ass. 21:2149, 1934.

45. Schoonover, I. C. and Souder, Wilmer: Corrosion of dental alloys. J. Amer. Dent. Ass. 28:1278, 1941 .

46. Easton, G. S.: Causes and prevention of amalgam failures. J. Amer. Dent. Ass. $28: 392,1941$.

47. Tingley, V. H. E.: The clinical use of amalgam. D. Items Interest. 62:608, 1940 .

48. Kornfeld, B.: Amalgam and silicate restorations. Dent. Outlook. 29:283, 1942 .

49. Healey, H. J. and Phillips, R. W.: A clinical study of amalgam failures. J. Dent. Res. 28:439, 1949.

50. Moss, R. P.: Amalgam failures. U.S. Armed Forces Med. J. 4:735, 1953 . 
51. Ingraham, Rex: The application of sound biochemical principles in the design of inlay, amalgam and gold foil restorations. J.Amer. Dent. Ass.40:402, 1950 .

52. Kroll, Abraham: New Look at an old friend--silver amalgam. New York J. Dent. 30:376, 1960.(Abst.)

53. Richardson, D. E.: Some considerations in preventing amalgam failures. S. Carolina Dent. J. 18:19, 1960 .

54. Hailey, Ray, Jr.: Why do amalgam restorations fail? Fortn. Rev. Chicago Dent. Soc. 41:17, 1961 .

55. Wiggins, E. T.: Amalgam failure and its prevention. Dent. Stud. Mag. $41: 399,1963$.

56. Wilson, C. J. and Ryge, Gunnar: Progress report on clinical study of amalgam fillings. J. Dent. Res. 40:773, 1961 . (Abst.)

57. Deschenes, G. H.: Reasons for amalgam filling failures. J. Canad. Dent. Ass. $28: 667,1962$. (Fr.)

58. Castaldi, C. R.: The management of some common paedodontic problems. J. Canad. Dent. Ass. 28:80, 1962 .

59. Fritz, J. W.: Etiology and prevention of fractures of amalgam restorations. J. Philipp. Dent. Ass. 14:21, 1961.

60. Simon, W. J.: Amalgam restorations, part I. J. Tenn. Dent. Ass. 29:7, 1949 .

61. Markley, M. R.: Restorations of silver amalgam. J.Amer. Dent. Ass. 43:133, 1951 . 
62. Miller, E. C.: Modern technic for building amalgam restorations. J. Wisconsin Dent. Soc. 28:199, 1952 .

63. Anderson, J. N.: Dental amalgam. Dent. Pract. (Bristol) 13:526, 1963 .

64. MacRae, P. D., Zacherl, W., and Castaldi, C. R.: Study of defects in Class II dental amalgam restorations in deciduous molars. J. Canad. Dent. Ass. 28:491, 1961 .

65. Bjorndal, A. M. and Sahs, E. A.: Comparative microphotographic study of marginal adaptation of amalgam and gold inlay restoration. Iowa Dent. J. 46:12, 1960 .

66. Hatt, S. D.: Relationship of amalgam to cavity wall. Dent. Pract. (Bristol) $10: 76,1959$.

67. Nelsen, R. J., Wolcott, R. B., and Paffenbarger, G. C.: Fluid exchange at the margins of dental restorations. J. Amer. Dent. Ass. 44:288, 1952.

68. Armstrong, W. D. and Simon, W. J.: Penetration of a radio-calcium at margins of filling materials: a preliminary report. J. Amer. Dent. Ass. 43: 684,1951 .

69. Philitps. R. W.: Research on dental amalgam and its application in practice. J. Amer. Dent. Ass. 54:309, 1957.

70. Weinstock, Alfred: Biophysical properties of silver amalgam--its use and abuse. J. Canad. Dent. Ass. 26:210, 1960 .

71. Phillips, R. W., Gilmore, W. H., Swartz, M. L., and Schenker, S. I. : Adaptation of restorations in vivo as assessed by $\mathrm{Ca}^{45}$. J. Amer. Dent. Ass. $62: 9,1961$. 
72. Brannstrom, Martin and Soremark, Rune: Penetration of $22 \mathrm{Na}$ ions around amalgam restorations with and without cavity varnish. Odont. Rev. 13:331 No. 4, 1962 .

73. Baumgartner, W. J., Bustard, R. E., and Feierabend, R. F.: Marginal leakage of amalgam restorations. J. Prosth. Dent. $13: 346,1963$.

74. Jorgensen, K. D.: Marginal fracture of amalgam fillings. Tandlaegebladet. 68:475, 1964. (Dan.)

75. Jorgensen, K. D.: Adaptability of dental amalgams. Tandlaegebladet. 68:378, 1964 . (Dan.)

76. Gabel, A. B.: The amalgam proximocclusal restoration in the deciduous molar. J. Dent. Child. 11:52, 2nd quarter, 1944.

77. Ireland, R. L.: Preservation of the primary teeth. J. Amer. Dent. Ass. 34:383, 1947 .

78. Brown, S. C.: Accepted operative procedures for deciduous and young permanent teeth. D. Items Interest. 71:579, 1949.

79. Brown, W. E.: A mechanical basis for the preparation of Class II cavities for amalgam fillings in deciduous molars. J. Amer. Dent. Ass. 38:417, 1949 .

80. Sweet, C. A.: Cavity preparation in deciduous teeth. J. Amer. Dent. Ass. $38: 423,1949$.

81. Noonan, M. A.: The use of photoelasticity in a study of cavity preparations. J. Dent. Child. 16:24, 1949 .

82. Lampshire, E. L.: Relation of cavity form to failure of silver amalgam restorations in primary molar teeth. M. S. Thesis, University of Nebraska, 1950. 
83. Lampshire, E. L.: An evaluation of cavity preparations in primary molars. J. Dent. Child. 22:3, 1955 .

84. Best, B. C.: Class II cavity preparation in primary teeth. J. Nebraska Dent. Ass. $38: 6,1962$.

85. Hartsook, J. T.: Principles involved in preparing proximocclusal cavities in deciduous teeth. J. Amer. Dent. Ass. $51: 649,1955$.

86. Castaldi, C. R.: Analysis of some operative procedures being used in paedodontics. J. Canad. Dent. Ass. 23:377, 1957 .

87. Mahler, D. B.: An analysis of stresses in a dental amalgam restoration. J. Dent. Res. 37:516, 1958 .

88. Ireland, R. L.: Cavity preparation and restoration for primary teeth. J. Tenn. Dent. Ass. 40:161, 1960 .

89. Ireland, R. L.: CIass II cavity preparation for primary teeth and its restoration with silver amalgam. Dent. Pract. (Bristol) 11:208, 1961 .

90. Ireland, R. L.: Operative procedures for children. J. Amer. Dent. Ass. 67:340, 1963 .

91. Ireland, R. L.: Operative procedures for children. J. Amer. Dent. Ass. 67:340, 1963 .

92. Mc Donald, R. E.: Pedodontics. St. Louis, C. V. Mosby Co., 1963, p. 243.

93. Kelsten, L. B.: Amalgam restorations for the primary dentition. J. New Jersey Dent. Soc. 23:33, 1952 . 
94. Ireland, R. L.: Operative technics for the tooth and the child. J. Amer. Dent. Ass. $32: 1083,1945$.

95. Ireland, R. L.: The management of cavities in the primary teeth. J. New Jersey Dent. Soc. $18: 5,1947$.

96. Klein, A. I.: The television microscope in dental research. Dental Progress. $3: 274,1963$.

97. Klein, A. I. and MacPherson, Dwight: Intra-oral television micromeasurement instrumentation. Unpublished manuscript, Indiana University Dental School.

98. Klein, A. I. and MacPherson, Dwight: Television measurement pulse generatormixed. Unpubiished manuscript, Indiana University Dental School. 
CURRICULUM VITAE 
November 13, 1937

June 3, 1955

March 26, 1956

March 1, 1957

December 6, 1957

May 1, 1958

June 1, 1959

June 4, 1962

$1962-1964$

1964-1966

August 15, 1965
Born in Raleigh, North Carolina

Graduated - Needham B. Broughton High School

Raleigh, North Carolina

Phi Eta Sigma

University of North Carolina

Chapel Hill, North Carolina

Delta Phi Alpha

University of North Carolina Chapel Hill, North Carolina

Phi Beta Kappa

University of North Carolina Chapel Hill, North Carolina

Order of the Old Well

University of North Carolina Chapel Hill, North Carolina

B. S. in Dentistry

University of North Carolina Chapel Hill, North Carolina

D.D.S., University of North Carolina School of Dentistry

Chapel Hill, North Carolina

Captain, Dental Corps, United States Air Force

Graduate Program - Pedodontics Indiana University

School of Dentistry

Indianapolis, Indiana

Married Michele Joy

LaBorwitt 
Professional Societies:

The American Dental Association

The American Society of Dentistry for Children

Alpha Omega Professional Dental Fraternity 
ABSTRACT 
THE INTRAORAL TELEVISION MICROMEASUREMENT OF CAVITY MARGIN DETERIORATION by Burton Allan Horwitz

The purpose of this study was to demonstrate the clinical application of the television microscope for direct intraoral micromeasurement of cavity margin deterioration. Niesiocclusal alloy restorations were placed in fifty-one maxillary second deciduous molars. A cast gold overlay with two proximal margin observation holes, one hole in the occlusal one-third and one hole in the gingival one-third, was fabricated for each restored tooth. The mesiobuccal proximal margins of the restorations were observed by the television microscope, and the marginal deterioration was electronically measured at intervals of one week, two weeks, four weeks, 12 weeks, 24 weeks, and 36 weeks postoperatively. The average gingival marginal deterioration ranged from 4.9 microns at one week to 37.8 microns at 36 weeks; the average occlusal marginal deterioration ranged from 5.4 microns at one week to 60.1 microns at 36 weeks. The data indicated that the gingival area of the proximal margin deteriorated at a faster rate during the first 12 weeks postoperatively, and the occlusal area of the gingival margin deteriorated at a faster rate during the last 24 weeks. Greater marginal alloy flash in the gingival area was believed to be responsible for the initial gingival deterioration, and repeated masticatory stresses was believed to be major causative factor for the occlusal deterioration during the last 24 weeks of the study。 